\title{
EL IUSNATURALISMO TOMISTA DEL SIGLO XX EN EsTADOS UNIDOS
}

\author{
ThOMISTIC IUS NATURALISM \\ of the Twentieth Century \\ IN THE UNITED STATES
}

O JUSNATURALISMO TOMISTA DO SÉcUlo XX NOS Estados Unidos

DIEGO POOLE*

orcid.org/0000-0002-9473-1327. Universidad Rey Juan Carlos, España. diego.poole@urjc.es

RECIBIDO: 13 DE MAYO DE 2017. ENVÍO A PARES: 15 DE MAYO DE 2017 APROBADO POR PARES: 12 DE JUNIO DE 2017. ACEPTADO: 30 DE JUNIO DE 2017 


\section{RESUMEN}

En este trabajo presentamos, en una visión panorámica, el iusnaturalismo tomista en la doctrina filosófico-jurídica de Estados Unidos desde principios del siglo XX hasta nuestros dias. Se concibe como una herramienta de trabajo para el estudioso del iusnaturalismo contemporáneo, una especie de "estado del arte" sobre la materia. Hay tres partes claramente diferenciadas: en la primera (apartados 1 al 7), la más extensa, después de una diferenciación conceptual básica entre la tradición de la ley natural (Natural Law Tradition) y la tradición de los derechos naturales (Natural Rights Tradition), se estudian cada uno de los autores más representativos, y se muestra el debate actual entre "neoclásicos" (Grisez, Finnis, George...) y "neoescolásicos" (Veatch, McInerny, Hittinger, Long, Jensen, etc.). En la segunda parte (apartado 8), se exponen los congresos o las conferencias periódicas que están teniendo lugar actualmente en Estados Unidos para debatir temas relacionados con el iusnaturalismo. Y en la tercera (apartado 9), se muestra una selección de los textos que consideramos más relevantes sobre el iusnaturalismo norteamericano del siglo XX.

\section{PALABRAS CLAVE}

Natural Law; New Natural Law; Natural Rights; Estados Unidos de América. 


\section{ABSTRACT}

In this article, the authors present an overview of Thomistic ius naturalism in the philosophical-juridical doctrine of the United States, from the beginning of the 20th century to the present day. It is conceived as a working tool for any student of contemporary natural law, a sort of "state of the art" on the matter. There are three clearly differentiated parts. In the first (paragraphs 1 to 7 ), which is the most extensive, a basic conceptual distinction is made between the tradition of natural law (Natural Law Tradition) and the tradition of natural rights (Natural Rights Tradition). Each of the most representative authors are examined, and the current debate between the "neoclassics" (Grisez, Finnis, George) and the "neoscholastics (Veatch, McInerny, Hittinger, Long, Jensen, etc.) is described. The second part (section 8) looks the congresses or periodic conferences that are now taking place in the United States to discuss issues related to natural law, while the third part (section 9) offers a selection of texts the authors of the article believe to be particularly relevant to North American ius naturalism in the twentieth century.

\section{KEYWORDS}

Natural Law; New Natural Law; Natural Rights; United States of America. 


\section{RESUMO}

Neste trabalho, apresentamos, numa visão panorâmica, o jusnaturalismo tomista na doutrina filosófico-jurídica dos Estados Unidos desde o início do século XX até os dias atuais. Concebe-se como uma ferramenta de trabalho para o estudioso do jusnaturalismo contemporâneo, uma espécie de "estado da arte" sobre a matéria. Há três partes claramente diferenciadas: na primeira (da seção 1 à 7), a mais extensa, após uma diferenciação conceitual básica entre a tradição da lei natural (Natural Law Tradition) e a tradição dos direitos naturais (Natural Rights Tradition), estuda-se cada um dos autores mais representativos e mostra-se o debate atual entre "neoclássicos" (Grisez, Finnis, George...) e "neoescolásticos" (Veatch, McInerny, Hittinger, Long, Jensen, etc.). Na segunda parte (seção 8), são expostos os congressos ou as conferências periódicas que estão acontecendo nos Estados Unidos para debater temas relacionados com o jusnaturalismo. Na terceira parte (seção 9), apresenta-se uma seleção dos textos que consideramos mais relevantes sobre o jusnaturalismo norte-americano do século XX.

\section{PALAVRAS-CHAVE}

Estados Unidos da América; Natural Law; Natural Rights; New Natural Law. 
Sumario: introducción. 1. Natural Law Tradition y Natural Rights Tradition. 2. Iusnaturalistas no tomistas. 3. Introducción del tomismo en Estados Unidos. 4. John C. Murray: el "pa-

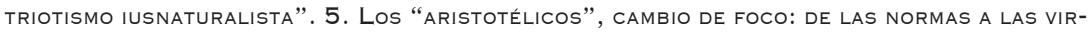
tudes. 6. Los “neoclásicos": la New Natural law Theory. 7. Los "neoescolásticos". 8. Revistas y congresos. 9. Selección bibliográfica. 10. Conclusiones. Bibliografía.

\section{INTRODUCCIÓN}

En este trabajo presentamos, en una visión panorámica, el iusnaturalismo tomista en la doctrina filosófico-jurídica de Estados Unidos desde principios del siglo XX hasta nuestros días, para que sirva de punto de partida a quienes quieran profundizar en cada una de las corrientes y de los autores tratados.

Antes de comenzar, es preciso dejar claro que el iusnaturalismo tomista en Estados Unidos ha sido siempre minoritario, aunque no por eso menos importante. Es más, estoy convencido de que actualmente es, en su conjunto, el más riguroso del mundo.

Durante el siglo XX, el pensamiento iusfilosófico dominante en Estados Unidos fue, por un lado, el progresismo que llevó al New Deal (p. ej. Woodrow Wilson, Charles Beard, Vernon Parrington, Hebert Croly), el pragmatismo de John Dewey, como la quintaesencia de la filosofía americana de la primera mitad del siglo XX, el realismo legalista y la jurisprudencia sociológica (los herederos de Holmes), y el cientifismo racionalista de la Segunda Guerra (ejemplificado en el behaviorismo en las ciencias sociales), todo enmarcado en el contexto de la filosofia analítica dominante en Estados Unidos. Tras la Segunda Guerra Mundial, especialmente por influjo de los intelectuales europeos que llegaron a Estados Unidos (Maritain, Gilson, Simon, Rommen...), hubo un resurgir del iusnaturalismo tomista, y, en general, un renovado interés en el pensamiento clásico. Pero pronto fue eclipsado por el liberalismo antiperfeccionista de John Rawls, y por la nueva izquierda que surgió en los años sesenta (Critical legal studies, feminismo, multiculturalismo, ideología de género...). ${ }^{1}$

1 En este ambiente reacio al iusnaturalismo, ciertamente hubo notables excepciones que confirman la regla. Una de ellas es el conjunto de artículos publicados por Edward Corwin en los años 19281929, en los que estudiaba el derecho natural en la teoría y práctica del derecho constitucional americano, implícito en la tradición del Common law (Cfr. Edward S. CoRwin, "The 'Higher Law' Background of American Constitutional Law", Harvard Law Review 42 (3) (1929), pp. 365-409). A principios de los años treinta siguieron los estudios del derecho natural en la jurisprudencia americana. En esta línea se enmarca la obra The Revival of Natural Law Concepts (1930), de Charles Haine, o el libro American Interpretations of Natural Law (1931), de Benjamin Wright. En cualquier caso, su objeto de estudio era más la práctica judicial que el análisis del trasfondo filosófico de la ley natural. En el tránsito del siglo XIX al XX hubo numerosas sentencias de los tribunales federales que anularon muchas leyes federales por no garantizar a los ciudadanos el adecuado proceso en decisiones estatales que restringian sus derechos. En cualquier caso, este revival "iusnaturalista" de los tribunales federales no encontró un eco suficiente en las universidades y menos todavía en el gran público. Como dice Hittinger, el verdadero resurgimiento del iusnaturalismo que tuvo lugar entre los años cuarenta y cincuenta en Estados Unidos, poco debía a esta tendencia de los tribunales federales, incluso tuvo que lidiar contra una especie de reacción contraria a los mismos jueces. 
Seleccionar autores supone, por definición, omitir otros. Lo cual es siempre discutible, no solo por la arbitrariedad del criterio de selección, sino también porque, dentro del criterio elegido, se pueden omitir otros pensadores. La extensión de este trabajo marca unos límites, pero también la capacidad de quien escribe. De antemano pido disculpas al lector, pero también su ayuda para que me sugiera las correcciones oportunas.

He estructurado este trabajo en dos partes: la primera, la más importante y con diferencia la más extensa (apartados 1 al 7), versa sobre las corrientes de pensamiento iusnaturalistas y los autores más significativos que han influido en Estados Unidos (norteamericanos la mayoría, no todos). La segunda (apartados 8 y 9), con recursos útiles para los que deseen profundizar en la materia, entre los que he distinguido, por un lado, las revistas periódicas iusnaturalistas más importantes y los congresos o encuentros académicos que reúnen cada año a autores iusnaturalistas (apartado 8), y por otro, una guía bibliográfica de referencia, con las publicaciones que al día de hoy considero más importantes para conocer el iusnaturalismo en Estados Unidos (apartado 9).

Dentro de la primera parte, en el primer apartado hago una distinción fundamental entre la Natural Law Tradition, que a grandes rasgos se identifica con el iusnaturalismo clásico aristotélico tomista, y la Natural Rights Tradition identificada con iusnaturalismo moderno individualista en su versión americana. En el segundo apartado veremos muy por encima una serie de autores especialmente influyentes, que sin ser plenamente iusnaturalistas en el sentido principal que daremos al término, lo son en cierto sentido. En el tercer apartado nos detendremos en la historia del resurgimiento del tomismo en Estados Unidos. En el cuarto, nos referiremos al iusnaturalismo de John Courtney Murray, que trata de vincular el alma americana con el iusnaturalismo clásico. En el quinto veremos los "aristotélicos", rótulo que empleamos para referirnos a autores que, sin ser plenamente tomistas, han influido decisivamente en el giro de la filosofia moral para que vuelva a centrar su atención en las virtudes y en el carácter personal, antes que en las normas de comportamiento. En el sexto apartado, titulado "Los 'neoclásicos", veremos con más profundidad el pensamiento de Germain Grisez, que Finnis y George proyectan sobre el mundo jurídico y político. Y, por último, en el séptimo apartado, bajo el título "Los neoescolásticos", nos detendremos en los autores tomistas más recientes, que desde los años ochenta del siglo pasado, en su continuo debate con los neoclásicos, han enriquecido la reflexión sobre la ley natural. ${ }^{2}$

La filosofia política y jurídica dominante durante los siglos XIX y XX, y, por tanto, casi toda la que se cultiva en Estados Unidos, cuando se ha ocupado de la ley natural lo ha hecho, al menos en su mayor parte, al margen de los estudios de la

2 La terminología empleada para designar estas categorias, "aristotélicos", "neoclásicos" y "neoescolásticos", no es muy apropiada, especialmente las dos últimas, pero ya se ha hecho común entre los autores para referirse entre ellos. Quizá lo más apropiado sería llamar a los neoclásicos "los defensores de la New Natural Law Theory" y a los segundos, "autores propiamente tomistas", pero esto es todavía más polémico, pues ambos grupos se consideran los mejores intérpretes de Santo Tomás. 
filosofia moral. La perspectiva jurídico-politica y la perspectiva moral han discurrido en paralelo ignorándose $\mathrm{y}$, muchas veces, despreciándose recíprocamente. Dada la separación entre hechos y valores, difundida en el pensamiento anglosajón desde David Hume, las teorías sobre la ley natural quedaban para los moralistas y los teólogos. Los juristas, cuando excepcionalmente se han referido a ellas, lo han hecho como tomando prestado un cuerpo extraño a su objeto de estudio, que, a modo de ideología, añadian sobre una ciencia jurídica ya configurada. Solo a partir de 1950 comienzan a abrirse camino doctrinas jurídicas, principalmente de corte tomista, donde moral y derecho se entrelazan sistemáticamente. Por tanto, no se extrañe el lector que traigamos a colación a autores que reflexionan sobre la ley natural sin ser la mayor parte de ellos expertos en derecho, incluso algunos teólogos, pero que también saben argumentar sin necesidad de apelar a la fe.

¿Qué entendemos por "iusnaturalismo”? Pocas expresiones de la filosofia jurídica, después de las de "derecho" y "justicia”, son tan polisémicas como las de "ley natural" y "iusnaturalismo". Se han utilizado para albergar concepciones muchas veces incompatibles entre sí. Ciertamente, no hay discusión en afirmar que iusnaturalistas son las corrientes de pensamiento que defienden la existencia de una ley natural que influye, de alguna manera, en el derecho positivo. En cambio, las diferencias se multiplican cuando se trata de definir el derecho, y mucho más todavía cuando se trata de definir la ley natural. No hay, por tanto, un iusnaturalismo, sino muchos, a lo largo de la historia y en la actualidad. En este trabajo, ¿a qué iusnaturalismo nos referimos?, ¿y por qué a ese y no a otro? Pues bien, aunque la elección parezca arbitraria, y ciertamente creo que lo es, vamos a establecer lo que los analíticos llaman un focal sense o caso central, un sentido principal de ley natural y de iusnaturalismo, como un núcleo duro, y una cierta periferia, no muy grande, donde ubicaremos algunos "casos cercanos" al sentido principal, que también podemos llamar "iusnaturalistas", aunque con menor propiedad.

¿Cuál es el focal sense elegido? La consideración tomista de la ley natural. Una ley entendida como participación de la razón humana en la ley eterna. O, dicho con otras palabras, la ordenación de la razón humana que confirma, encauza y concreta el impulso natural hacia la plenitud de la propia forma (la realización humana), impulso que está impreso por Dios en todas las potencias del hombre. A partir de aquí nos podemos separar más o menos, y, por tanto, considerando más o menos iusnaturalista una doctrina.

El iusnaturalismo tomista, elegido como focal sense de nuestra reflexión, se enmarca en una corriente más genérica que conviene distinguir de la tradición de los derechos naturales desarrollada en la modernidad. Para seguir una terminología empleada por diversos autores que vamos a tratar aquí, llamaremos a la primera Natural Law Tradition (NLT), y a la segunda Natural Rights Tradition (NRT). ${ }^{3}$

3 John Courtney Murray, en We Hold These Truths (1960), Maryland, Sheed \& Ward, 2005, utiliza esta terminologia, y también Christopher Wolf en su capitulo "Thomistic natural law and the american natural law tradition", en St. Thomas Aquinas and the Natural Law Tradition, Washington D.C., The Catholic University of America Press, 2004, pp. 197 y ss. Se puede decir que la NLT se 


\section{NATURAL LAW TRADITION y NATURAL RIghtS TRADITION}

Es un lugar común la idea de que el iusnaturalismo clásico pervive en la actual teoría de los derechos humanos, y que la filosofía politica sobre la que se fundó Estados Unidos fue profundamente iusnaturalista. Una afirmación semejante, por decirlo suavemente, requiere muchas matizaciones.

La filosofía jurídica que sirvió de inspiración a los padres fundadores de Estados Unidos fue principalmente la de John Locke, ${ }^{4}$ cuya obra se enmarca en la Natural Rigths Tradition (NLT), frente a la Natural Law Tradition (NRT), cuyo exponente más significativo fue Santo Tomás. Las diferencias fundamentales entre ambas tradiciones las podemos resumir en tres.

Primero, participación frente a inmanencia. La NLT considera la ley natural como participación de la razón humana en la razón divina que gobierna el cosmos, y vincula directamente la ley natural con la acción de Dios como origen y como fin del cosmos. La NRT, en cambio, no considera la ley natural como una participación en la ley eterna, sino como mero resultado de la inclinación o de verdades evidentes en sí mismas (puestas por Dios, según Locke).

Segundo, ley de la comunidad frente a ley del individuo. En la NLT, la ley natural es ley de la comunidad, no solo ley del individuo. La NLT considera que mediante la ley natural el hombre se integra libremente en un orden superior, que engloba toda la naturaleza creada. El bien común es una expresión analógica que se predica de las diversas comunidades concéntricas en las que el hombre libremente, pero de manera natural, participa. En cambio, desde la perspectiva de la NRT, en el estado de naturaleza el hombre se presenta como un individuo autosuficiente, un átomo compacto y completo en medio de otros átomos compactos y completos, todos solitarios y cerrados en sí mismos. La idea del hombre es la de un individuo que es "absolute lord of his own person and possessions, equal to the greatest, and subject to nobody", como dice Locke en su segundo ensayo. ${ }^{5}$ Desde esa perspectiva, la libertad humana se identifica con esa soberanía o independencia del individuo, sobre la que descansa la única ley, la ley de la naturaleza, con un solo precepto: el de la autoconservación (self preservation): la conservación de su propia vida, libertad y propiedad. Y esta ley tiene una sola limitación: el respeto a la soberana independencia de los demás. Por tanto, la premisa de ese hipotético estado de naturaleza es la negación de la estructura naturalmente sociable del ser humano, y la afirmación de que el estado civil es un artificio, no estrictamente

corresponde con el iusnaturalismo clásico, mientras que la NRT se identificaría con el iusnaturalismo moderno que surge a partir del siglo XVII, especialmente desde Hobbes en adelante.

4 Ciertamente los fundadores de Estados Unidos se basaron también en otras fuentes, especialmente en la tradición del Common Law inglés, y de autores como Christopher St. Germain y Edward

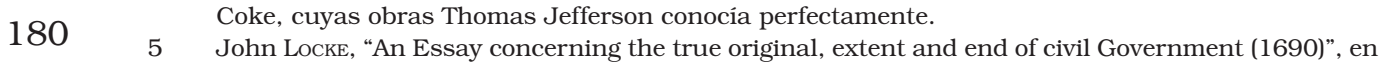
Two Treatises on Government, London, R. Butler \& others, 1821, cap. 9, §123, en www.bartleby. com/169/ 
necesario para el completo desarrollo del hombre como tal, sino solo una convención útil para la mejor protección de los individuos en cuanto tales (el utilitarismo de Bentham no es más que la prolongación lógica del pensamiento de Locke). Como consecuencia, se deja de concebir la sociedad como una realidad orgánica, entrelazada en formas ascendentes de sociabilidad exigidas por la naturaleza humana. En cambio, para la NRT todas las formas de sociabilidad son puramente contractuales, y no tienen más fundamento que la libertad humana. El "bien común" no es nada real en sí mismo, no es un bien social cualitativamente distinto de todos los bienes individuales, sino un mero simbolo para designar una suma cuantitativa de intereses individuales. La justicia legal y la distributiva son reducidas al modelo contractual, al modo de la justicia conmutativa. La voluntad de los contratantes crea no solo las instituciones políticas, sino el mismo bien común, que se convierte en la suma de las voluntades individuales.

Tercero, maximalismo frente a minimalismo ético. Por contraste con la NRT, en la NLT la ley natural busca la plenitud personal, ${ }^{6}$ el summum bonum, que se logra mediante la correcta disposición del hombre en la comunidad universal, a través de la correcta participación en las comunidades intermedias (de ahí la profundidad del significado que tiene el decir que la ley es "ordenación al bien común"). La NLT se orienta hacia la plena realización humana, en una visión donde el hombre se contempla como parte natural de un todo orgánico, que lo precede y lo vincula, y en cuyo encaje encuentra la perfección. Por contraste, la NTR se orienta solo hacia el individuo, y ya no se preocupa de su perfección, sino de la evitación del sumo mal, la pérdida de la propia vida, relegando a la esfera privada la plena realización humana.

¿Por qué en Estados Unidos no se apreció tanto la ruptura entre la NLT y la NRT? $\mathrm{Al}$ menos por tres razones.

Primero, porque a diferencia de lo que sucedió en la Francia revolucionaria, inspirada igualmente por el iusnaturalismo moderno, los padres fundadores de Estados Unidos se movian en el ámbito de la cultura jurídica iusnaturalista del Common law. ${ }^{7}$

6 Algunos, utilizando una terminología de John Rawls, pueden argumentar que la diferencia más importante entre NLT y NRT está en que la primera pretende ser una filosofia moral comprensiva, mientras que la NRT tiene una pretensión más modesta, meramente política, sobre los límites del Gobierno, en lugar de preocuparse por la perfección personal. Pero la cuestión no es tan simple, por varias razones. Primero, porque las doctrinas de la NRT están también influidas por consideraciones éticas, metafísicas, religiosas (quizá porque en el siglo XVII se daban por obvias en Inglaterra). Segundo, porque la doctrina política liberal, al menos de Locke, daba por descontado la inmoralidad de ciertas conductas: asesinato, robo, adulterio, difamación, etc. Y tercero, porque en la NRT está implícita la prioridad de la paz y de la seguridad.

$7 \quad$ Heinrich A. Rommen subraya la tenacidad con la que el espíritu del Common Law inglés mantuvo las ideas de ley natural y de equidad, que había asimilado durante la Edad Media católica, especialmente por la influencia de Henry Bracton (+1268) y de Sir. John Fortescue (+ aprox. 1476). Cfr. Heinrich A. Rommen, The Natural Law: A Study in Legal and Social History and Philosophy (1936 vers. original alemana), Indianapolis, Liberty Fund, 1998, pp. 100-101. 
Segundo, porque en el ambiente en que nació Estados Unidos se daba por descontado el valor de la religión y de la familia, y, por tanto, de los organismos intermedios entre el Estado y el individuo. Murray lo explica con gran claridad:

... el entusiasmo francés que aceptó las ideas [de Locke] no tuvo los contrapesos impuestos sobre Locke por el sentido común británico, su mesura, y su respeto por la tradición. En consecuencia, cuando su ley de la naturaleza pasó a través de la irresponsable razón política [de los revolucionarios franceses], desembocó en el completo atomismo social de la Constitución de 1791 y de la Declaración de los derechos del hombre y del ciudadano. Donde resultaron solo dos soberanias: la del individuo sobre su vida privada, y la del Estado sobre todas las formas de vida social. Ahí no hay formas sociales autónomas intermedias entre los individuos y el Estado [...] Ciertamente los americanos no derivaron todas las consecuencias lógicas de la teoría de Locke, pero los franceses sí. Por ejemplo, la teoría doctrinaria de Montesquieu de que solo el poder controla el poder, y de que cuando ese control es adecuado, surge como resultado quasi mecánico la libertad. Más todavía, el artículo 4 de la Declaración de derechos del hombre, siguiendo la lógica de la doctrina de Locke, establece que los "límites" de los derechos individuales "solo pueden ser establecidos por la ley", por la ley positiva, se entiende. Aquí se ve la negación explícita de un ordo iuris anterior al Estado. Ahí está la semilla del positivismo legalista (que luego en los Estados Unidos se impondrá por el activismo judicial) y la esencia de la omnipotente democracia de Rousseau, en la que hay una completa identificación entre Estado y comunidad nacional, y el consecuente sometimiento de toda forma de vida en común al control total del Estado. ${ }^{8}$

Tercero, porque Locke parecía seguir la tradición iusnaturalista con sus continuas referencias a Dios, ${ }^{9}$ con su admiración hacia el "juicioso Hooker", anglicano con-

8 John C. Murray, We hold these truths, op. cit., cap. XIII, epigrafe "The law of nature" [Kindle version, pos. 4915]. Igualmente, el TS norteamericano reflejaba una visión de la sociedad que distaba mucho de la francesa, en la que la consideración jurídica de la ley natural iba más allá del derecho de propiedad. Por ejemplo, en la St. Bradwel vs. Illinois, sobre la familia en 1873: "La constitución de la organización familiar, fundada en la ordenación divina, así como en la naturaleza de las cosas”, sobre la unidad de la familia basada en la complementariedad natural. Otro ejemplo es la sentencia del TS 1923 Meyer vs. Nebraska, que consideraba una ley de Nebraska que prohibía la enseñanza en las escuelas de una lengua diferente del inglés: defiende el "el deber natural de los padres de proporcionar a sus hijos una educación adecuada según su edad”. Y un tercer ejemplo, quizá la única sentencia del TS (Pierce vs. Sisters, 1925) que funda su decisión en una encíclica del papa (Pio XI, Divini Illius Magistri), sobre la educación cristiana, contra una ley del Estado de Oregon que imponía la educación en centros públicos a todos los niños: "El niño no es una mera criatura del Estado; aquellos que lo crian y dirigen su destino tienen el derecho, unido a su alto deber, para instruirle y prepararle para obligaciones adicionales".

9 Por ejemplo, en el Segundo Tratado (sobre el gobierno civil, antes citado) leemos "porque, siendo todos los hombres hechura de un Creador todopoderoso e infinitamente sabio, servidores todos de un Dueño soberano, enviados al mundo por orden del Él y a su negocio, propiedad son de Él, y como hechuras suyas deberán durar mientras Él, y no otro, gustare de ello" (cap. 2, §6). Por otra parte, desde el nacimiento de Estados Unidos, en su cultura jurídica estaba presente la fundamentación en Dios de la ley natural. Por ejemplo, en la voz "ley natural" de la Enciclopedia Americana, editada por Francis Lieber en 1832, podemos leer el texto del juez Joseph Story: "Para el objetivo del presente artículo, asumiremos, sin tratar de probarlo, que existe un Dios de poder infinito, conocimiento, sabiduria, bondad, justicia y misericordia; que ha creado al hombre con las capacidades y facultades necesarias para buscar y conseguir la felicidad; que el hombre es un ser 
siderado como representante de la vieja tradición de la ley natural; e igualmente, por algunas distinciones conceptuales como libertady licencia, que nos recuerdan la idea clásica de una libertad finalizada.

\section{IUSNATURALISTAS NO TOMISTAS}

Entre los filósofos del derecho a los que podríamos considerar en la periferia del focal sense, y que más han influido en Estados Unidos, nos referiremos brevemente a Alessandro Passerin d'Entrévès, Ronald Dworkin, Lon Fuller, Leo Strauss y Eric Voegelin.

Alessandro Passerin d'Entrevés, profesor italiano (Turín, 1902-1985), influyó en la en la filosofía jurídica y política norteamericana de mediados del siglo XX. Subrayaba la importancia del iusnaturalismo como límite al poder político. En 1951 publicó su libro Natural Law ${ }^{10}$ que, si bien se aparta en algunas cuestiones sustanciales del pensamiento tomista, contiene una profunda reflexión en defensa de la ley natural. Este pequeño tratado, escrito por un profesor de Teoría Política en la Universidad de Turín, maestro de Bobbio, que también fue profesor en la Universidad de Oxford y visitante en Yale, reintrodujo en el ámbito de la ciencia jurídica y politica angloamericana conceptos básicos del iusnaturalismo clásico. La segunda edición del libro apareció en 1970 con tres apéndices: el primero (A), titulado "The Case for Natural Law Re-Examinated", es una profunda apologia del iusnaturalismo; este apéndice se publicó originalmente en un artículo en Natural Law Forum (del que luego hablaremos). El segundo apéndice (B) trata sobre diversas versiones iusnaturalistas. Y el tercero (C) es un análisis de la teoría de Hart sobre las necesidades naturales.

La doctrina de Ronald Dworkin (1931-2013), el estadounidense más influyente de los filósofos del derecho en el último tercio del siglo XX, está contenida en sus tres grandes obras: Taking Rights Seriously (1977), A Matter of Principle (1985), and Law's Empire (1986). Catalogarlo como iusnaturalista puede resultar excesivo, teniendo en cuenta que los principios a los que él se refiere son principalmente valores sociales, más que valores derivados de la naturaleza humana, pero concedámoslo al menos en atención a la manera en que él mismo se autocalifica de iusnaturalista: "Si la cruda descripción de la ley natural que acabo de dar es correcta, esto es, que es iusnaturalista toda teoría que defienda que el contenido de la ley depende a veces de la adecuada respuesta a algunas cuestiones mora-

moral, dependiente y responsable; que su alma es inmortal; que su felicidad última o miseria depende de su propia conducta; que en el futuro habrá una retribución, de acuerdo con la sabiduría y bondad divinas; que por el correcto ejercicio de sus capacidades y facultades, el hombre siempre puede discernir y seguir su deber; que la virtud, o el hacer bien a la humanidad de acuerdo con la voluntad divina, tiene asociado el premio de una felicidad inmortal; y que el vicio, o el hacer el mal, desobedeciendo esa voluntad, está, por la misma constitución de la naturaleza humana, necesariamente relacionada con el sufrimiento y la miseria, directamente o al final. En breve, que el hombre no puede ser permanentemente feliz practicando el vicio, debe ser permanentemente feliz con la práctica de la virtud" (traducción propia).

10 Alessandro PAsserin D’Entreves, Natural Law, New York, Hutchinson University Library, 1951 (trad. it. La dottrina del diritto naturale, Torino 1954). 
les, entonces soy culpable de [defender] la ley natural". ${ }^{11}$ Este planteamiento nos lo encontramos ya en Harry Jones, profesor de Columbia University (+1983), que trató de reconciliar las diferencias entre los defensores de la ley natural y los seguidores del realismo jurídico apelando a los principios morales que influyen en las decisiones judiciales, al indicar que las exigencias de la ley natural están presentes en el proceso de creación del derecho de cada caso.

Por su parte, Lon Fuller (1902-1978), ${ }^{12}$ en su Morality of Law (1964) desarrolla el concepto de "derecho natural procedimental" (procedural natural law), donde explica la necesidad de argumentos racionales en el arte de legislar. En 1958, la Harvard Law Review publicó un extenso debate entre Hart y Fuller sobre las relaciones entre ética y derecho, donde se muestra claramente la tesis de Fuller sobre la función de la ley natural como contenido básico imprescindible de toda ley positiva para que esta tuviera algún sentido. Como dice Anthony Lisska, a mediados del siglo XX, en la doctrina jurídica de Estados Unidos, el nombre de Fuller iba siempre asociado al de iusnaturalismo. ${ }^{13}$

Leo Strauss (1899-1973), de origen alemán, llegó a Estados Unidos en 1938. Después de un periodo de docencia en la New School for Social Research (New York), trabajó durante casi veinte años como profesor de ciencia política en la Universidad de Chicago (1949-1969), por entonces, junto con Notre Dame, el mayor centro de reflexión iusnaturalista de Estados Unidos. Strauss, al igual que Voegelin, contribuyó a situar la reflexión sobre la ley natural en el contexto de la filosofía política clásica y contemporánea. Su obra Natural Right and History (1953), un compendio de las lecciones que impartió en Chicago, es una obra fundamental para comprender la relación entre filosofia, sociedad y política, al tiempo que es una crítica al relativismo de las doctrinas historicistas. Strauss defiende la posibilidad de conocer unos valores objetivos, que trascienden la historia, y que deben informar toda legislación que pretenda ser justa. Cuando los griegos des-

11 Vale la pena reproducir (sin traducir) la consideración como iusnaturalista que hace Dworkin de sí mismo: "Everyone likes categories, and legal philosophers like them very much. So we spend a good deal of time, not all of it profitably, labeling ourselves and the theories of law we defend. One label, however, is particularly dreaded: no one wants to be called a natural lawyer. Natural law insists that what the law is depends in some way on what the law should be. This seems metaphysical or at least vaguely religious. In any case it seems plainly wrong. If some theory of law is shown to be a natural law theory, therefore, people can be excused if they do not attend to it much further. In the past several years, I have tried to defend a theory about how judges should decide cases that some critics (though not all) say is natural law theory and should be rejected for that reason. I have of course made the pious and familiar objection to this charge, that it is better to look at theories than labels. But since labels are so much a part of our common intellectual life, it is almost as silly to flee as to hurl them. If the crude description of natural law I just gave is correct, that any theory which makes the content of law sometimes depend on the correct answer to some moral question is a natural law theory, then I am guilty of natural law. I am not interested, I should add, in whether this crude characterization is historically correct, or whether it succeeds in distinguishing natural law from positivist theories of law. My present concern is rather this. Suppose this is natural law. What in the world is wrong with it?" Ronald DwoRkin, "Natural law revisited", University of Florida Law Review 34 [1977] (1982), cap. 1, § 2, reeditado en muchas otras publicaciones.

18412 Cfr. Diego Poole, “Lon Fuller”, en Juristas Universales, vol. IV, Madrid, Marcial Pons, 2004, pp. 391 y ss.

13 Anthony Lisska, Aquinas's Theory of Natural Law: An Analytic Reconstruction, Oxford, Clarendon Press, 1998 (cito de la version Kindle, pos. 366). 
cubrieron la naturaleza, explica Strauss, descubrieron la filosofia, que comenzó precisamente como una interpretación de la primera, y el concepto de derecho natural se asoció desde sus orígenes con la gente sabia, que formulaba criterios universales de comportamiento a partir de su estudio de la naturaleza. Strauss presta especial atención a la diferencia entre el iusnaturalismo clásico (griego y medieval) y el que surge a partir de Hobbes, y critica duramente la idea de estado de naturaleza original, especialmente en Hobbes, Locke y Rousseau. La influencia de Strauss sobre los politicos conservadores norteamericanos es indiscutida. ${ }^{14}$

Eric Voegelin (1901-1985), llegó a los Estados Unidos en 1938, procedente de Alemania, el mismo año que Strauss y Rommen. Durante su primera estancia en este país trabaja como profesor de ciencia politica en la universidad estatal de Louisiana hasta 1958, cuando regresa a Alemania para enseñar durante diez años en Munich. En 1969 vuelve a Estados Unidos donde permanecerá, hasta su muerte, en la Universidad de Stanford. La obra que sin duda más nos interesa es The Nature of the Law, un ensayo sobre la naturaleza de la ley, escrito en 1957, publicado en 1991 en la colección de sus obras completas. ${ }^{15}$ Este pequeño libro es una obra maestra del iusnaturalismo y una crítica del positivismo legalista, que ha influido en los iusnaturalistas de la segunda mitad del siglo XX, de modo especial en John Finnis. Para Voegelin, la naturaleza de la ley está estrechamente relacionada con la naturaleza del hombre. La ley es la expresión del orden sustancial de la realidad. Las leyes humanas son expresiones históricas del orden exigido por la verdadera ley. ${ }^{16}$

\section{INTRODUCCIÓN DEL TOMISMO EN ESTADOS UNIDOS}

Hasta la década de los veinte, el tomismo norteamericano en realidad solo existía en las bibliotecas de las órdenes religiosas. ${ }^{17}$ Los intelectuales norteamericanos, fuera del ámbito estrictamente religioso, que en el siglo XX abrazaron el tomismo

14 Leo Strauss, "perhaps the most influential political thinker of the generation of Americans that spanned the mid-point of the twentieth century". Walter NicGorski, "Leo Strauss", Modern Age 26 (1982), p. 270. "His impact has stretched far and wide. Supposedly, a cadre of "neoconservatives" both within the Bush administration and without were influenced by Strauss' thought, including, but not limited to, Richard Perle, Paul Wolfowitz, William Kristol, Robert Kagan, Abram Shulsky, Irving Kristol and Harvey Mansfield, Jr. He has also had impactful students and colleagues that he's directly influenced, including Walter Berns, Allan Bloom, Joseph Cropsey, Harry Jaffa, Martin Diamond and Herbert Storing. His thought is so significant that followers of his have their own name - 'Straussians'. More conservative-inclined followers of Strauss have taken to calling themselves, in the same vein as the virulent conservative split between 'neocons' and 'paleocons', 'Leocons"'. Tony Petersen, "Leo Strauss, natural right and history", en https://goo.gl/5IUOta. Fecha de consulta: 30 de febrero de 2017.

15 Eric Voegelin, "Nature of the law and related legal writings", en The collected works of Eric Voegelin, vol. 27, Columbia (MO), University of Missouri Press, 1991.

16 Para un estudio ordenado, breve y muy clarificador del iusnaturalismo de Voegelin, véase Patrick H. MARTIN, "Natural law: Voegelin and the end of [legall philosophy", Louisiana Law Review 62 (3) (2002).

17 Florian Michel señala que no hubo verdadero tomismo en Estados Unidos hasta las décadas de los veinte y treinta, a pesar de las recomendaciones de León XIII y Pío X. Ver Florian Michel, La Pensée Catholique en Amérique du Nord (Réseaux Intellectuels et Échanges Culturels entre l'Europe, le Canada et les Etats-Unis), París, Desclée de Brouwer, 2010. 
lo hicieron, como enseguida veremos, principalmente bajo la influencia de autores como Étienne Gilson, Jacques Maritain, Mortimer J. Adler, Robert M. Hutchins, Charles de Koninck, Yves Simon, Paul Sigmund y Heinrich Rommen.

¿Cómo llega el tomismo a la ciencia jurídica de Estados Unidos? Tras la publicación en 1879 de la encíclica Aeterni Patris por el Papa León XIII, en la que se instaba a los cristianos a profundizar en las enseñanzas de Santo Tomás, en Europa hubo un resurgir del tomismo, y, por consiguiente, de la reflexión sobre la ley natural. ${ }^{18}$ Poco después de la Aeterni Patris, se realizó en Europa la primera gran edición crítica del corpus tomista (edición leonina), comenzada en 1882 y finalizada en 1906. ${ }^{19}$ Ciertamente, este renacer se dio al principio en el ámbito de influencia de los centros de enseñanza vinculados a la Iglesia católica. Lovaina fue el centro más representativo de este resurgir tomista, pero estuvo marcado por una rígida metafísica (Divus Thomas semper formalissime loquitur, fue uno de sus lemas). Los filósofos anglosajones siguieron mayoritariamente en la órbita de la filosofia analítica.

Tras la Segunda Guerra Mundial, a la vista de los crimenes contra la humanidad, se puso en entredicho el positivismo jurídico dominante, y hubo un resurgir del pensamiento iusnaturalista para justificar los derechos inalienables que poseen todos los hombres con anterioridad a su reconocimiento legal.

18 León XIII publicó más de ocho encíclicas sobre cuestiones sociales, como los derechos de los trabajadores, las relaciones entre la Iglesia y el Estado, o sobre el origen de la autoridad política. La doctrina social cristiana cobraba cada vez más importancia en el contexto de las crisis desatadas por las dos guerras mundiales, el auge del fascismo o la Gran Depresión norteamericana. Sobre el cuerpo de esta doctrina, Hittinger destaca dos puntos de especial relevancia para el iusnaturalismo: "El primero es que estas encíclicas suponian un extenso corpus de doctrina sobre la ley natural aplicada a cuestiones grandes y pequeñas, desde el problema del socialismo y el derecho de propiedad privada hasta la moralidad del duelo. El segundo punto [...] las encíclicas proveían un modelo de integración de dos perspectivas filosóficas, que no habían sido relacionadas con éxito por las doctrinas iusnaturalistas de la neoescolástica [moderna]. Por un lado, las encíclicas eran 'conservadoras' en la comprensión intelectual de la ley natural y bastante tradicionales sobre determinadas cuestiones de comportamiento; por otro lado, eran prácticamente 'liberales' en muchas de las grandes cuestiones políticas de la modernidad. Por ejemplo, favorecian el principio de subsidiariedad contra los poderes prácticamente ilimitados de los estados modernos; apoyaban el derecho del pueblo para elegir entre diversas formas de gobierno; apoyaban el derecho de los individuos a organizarse en sindicatos, a tener propiedades, a gozar de libertad religiosa”. Russell HitTinger, Introducción a Rommen, H., The Natural Law: A Study in Legal and Social History and Philosophy (1936 vers. original alemana), Indianapolis, Liberty Fund, 1998.

19 Hasta la invención de la imprenta a mediados del siglo XV, las obras de Santo Tomás se difundieron en manuscritos por toda Europa. Tras la invención de la prensa, se multiplicaron las ediciones en Alemania, Francia e Italia, especialmente de la Suma Teológica. La primera edición impresa que se conoce es la que hizo Peter Schoeffer de la "Secunda Secundae", en 1467 en Mainz. Sin embargo, la primera edición completa de la Suma Teológica se realizó en Basilea, en 1485. Las ediciones principales de las obras completas de Santo Tomás son: Roma, 1570; Venecia, 1594, 1612, 1745; Amberes, 1612; París, 1660, 1871-80 (Vives); Parma, 1852-73; Roma 1882 (la Leonina). La edición romana de 1570, llamada "la Piana" (trae el nombre de Pío V, que la mandó editar) fue la edición principal durante muchos años. Esta edición contenía los comentarios del cardenal Cayetano. En 1880, por el Motu proprio del 18 de enero de 1880 de León XIII, se comienza la edición más elaborada de todas hasta la fecha (conocida como la "edición leonina"). El último volumen de la edición leonina vio la luz en 1906. 
Pero la historia fuerte del tomismo en Estados Unidos empieza con la llegada de Étienne Gilson (1884-1978) a Harvard en 1926 como profesor visitante, aceptado en dicha universidad no tanto por admiración hacia su doctrina, como por el talante de Harvard, abierta a las distintas corrientes de pensamiento.

Étienne Gilson, después de un tiempo en Harvard (rechazó la oferta de una plaza fija en dicha universidad), pasó a colaborar activamente en la fundación del Instituto Pontificio de Estudios Medievales en la Universidad de Toronto (Canadá). Desde su fundación en 1928, este Instituto formó a los intelectuales que sentaron las bases de los estudios medievales y tomistas de las universidades católicas de Estados Unidos, en lugares como Marquette (Wisconsin) o Notre Dame (Indiana). Toronto se convirtió también en la cabeza de playa de otros tomistas franceses que vendrian a América del Norte. Y entre ellos, el más destacado fue sin duda Jacques Maritain.

Jacques Maritain (1882-1973) fue un autor decisivo en el resurgir de iusnaturalismo tomista en Estados Unidos. En 1951 publica Man and the State, una filosofia politica elaborada sobre bases tomistas, en la que se expone toda una teoría de los derechos humanos. Maritain llegó a Estados Unidos en los años treinta, y aunque apreciaba a Gilson, se oponía resueltamente al tradicionalismo de los tomistas de Quebec (afincados en la Universidad de Laval), liderados por Charles de Koninck. ${ }^{20}$ Maritain pensaba que la cultura democrática liberal remozada con el tomismo era la mejor alternativa al nihilismo existencialista que actuaba como disolvente de toda filosofia moral y política fundada en la naturaleza.

En 1933, Maritain aceptó la invitación de Robert Hutchins (presidente de la Universidad de Chicago) y de Mortimer Adler para participar en la Universidad de Chicago en lo que ellos consideraban una verdadera "guerra civil cultural", y que ciertamente fue el germen del debate que se extendería por Estados Unidos desde los años sesenta hasta nuestros dias. Como dice Florian Michel, la batalla se daba entre los que aceptaban la metafísica como ciencia (Hutchins, Adler y Maritain) y aquellos que no (John Dewey y sus seguidores en la filosofia y las ciencias sociales, de corte pragmatista, naturalista, evolutiva, relativista y utilitaria). Hutchins quería reformar la Universidad de Chicago haciendo de la metafísica el culmen de sus planes de estudio. Tras haber sido nombrado presidente de la Universidad, comenzó a planear la creación de una línea de investigación y enseñanza aristotélica de humanidades, con Mortimer Adler como su hombre fuerte.

Mortimer Adler (1902-2001), profesor de filosofia jurídica en la Universidad de Chicago, junto con Hutchins, promovió la lectura de los grandes clásicos. Ambos

20 Charles De Koninck (1906-1965), de origen belga, afincado en Canadá, estudió filosofia en la universidad católica de Lovaina, donde abrazó el tomismo. En 1934 comenzó a enseñar en la universidad de Laval (Toronto). Fue amigo intimo de Antoine de Saint-Exupéry (se dice que este se inspiró en el hijo de De Koninck para escribir El principito). De Koninck se opuso al personalismo de Maritain: en su obra De la primauté du bien commun contre les personnalistes (Laval, 1943) reafirmaba la primacía del bien común sobre el bien personal. Fue director del Departamento de Filosofía de la Universidad Laval. 
publicaron en 1952, en cincuenta y cuatro tomos, Great Books of the Western World (Grandes libros del mundo occidental), editados por la Enciclopedia Británica. Adler recomendaba a sus estudiantes la lectura de Aristóteles y de Santo Tomás, especialmente en lo relativo a la moral y al derecho, argumentos válidos para abordar también muchos problemas jurídicos de la actualidad. Junto con Hutchins trató de convertir la Universidad de Chicago en un centro reconocido por su difusión y estudio de Aristóteles y Santo Tomás. Por su parte, el Hutchins's Institute, en Santa Barbara (California), fue una de las sedes donde más seriamente se reflexionó sobre la ley natural en los años cincuenta y sesenta. Parte de los resultados de esas investigaciones se publicaron en Natural Law and Modern Society en 1963, ${ }^{21}$ Adler publicó Aristotle for Everybody en $1978 .{ }^{22}$ Y en 1990, en su colección de ensayos publicados bajo el título Reforming Education: The Opening of the American Mind, ${ }^{23}$ se deja ver con toda claridad la impronta aristotélicotomista de sus argumentos. "A mi juicio —escribía Adler- la Ética a Nicómaco de Aristóteles es la única filosofía moral sana, práctica y antidogmática en toda la tradición de Occidente". ${ }^{24}$ Adler tradujo al inglés la obra de Maritain, Scholasticism and Politics (1940).

Adler se oponía resueltamente al sociólogo e ingeniero social Louis Wirth, también docente en la misma universidad, acerca del propósito de la educación, de la filosofia, de la universidad y del papel de Estados Unidos ante la Segunda Guerra Mundial que se avecinaba. Wirth pensaba que los docentes católicos no debían enseñar en su universidad y que el tomismo era la mayor amenaza contra la libertad. Para contrarrestar esta presencia, Wirth y los suyos (especialmente Sidney Hook y Eduard Shils) trajeron en 1935 a Chicago a Rudolph Carnap y a otros miembros del Círculo de Viena. Y metieron a Bertrand Russell en el Departamento de Filosofia. Frank Knight se unió a la cruzada anticatólica en Chicago, actitud que refleja en su "Natural Law: Last refuge of the bigot". ${ }^{25}$ Todos ellos veían a Maritain y Adler como agentes de la propaganda católica.

La estrategia de Wirth fue mucho más eficaz que la de Maritain, Hutchins y Adler. Como buen sociólogo y pragmático, se sirvió especialmente de la prensa escrita, la radio, la televisión y el cine para minar la moral católica. Por eso, Wirth consideraba que cualquier tipo de diálogo con Maritain y los suyos era innecesario. Probablemente había aprendido la misma lección de Wilhelm Reich, en Viena, sobre la desintegración de la moral cristiana, que se consigue de un modo mucho más eficaz por la corrupción de las costumbres que por el debate intelectual.

Pero volvamos a Maritain. Él estaba convencido de que Chicago era el lugar ideal para que el tomismo penetrara en la cultura estadounidense. Y pensaba que la

21 AAVV, Natural Law and Modern Society, New York, The World Publishing Company, 1963. En este libro hay también un artículo de Hutchins titulado "Natural Law and Jurisprudence".

22 Mortimer AdLer, Aristotle for everybody, New York, Tochstone, 1978.

188 Mortimer AdLer, Reforming Education: The Opening of the American Mind, New York, Collier Books and Macmillan, 1990.

24 Ibid., p. 254.

25 Frank H. Knight, “Natural law: Last refuge of the bigot”, en Ethics 59 (2) (1949), pp. 127-135. 
Universidad de Notre Dame era el mejor lugar para que el tomismo madurara como una filosofia de excelencia. De este modo, en los años cuarenta se puso en funcionamiento su propio instituto medieval, inspirado en el que Gilson desarrolló en Toronto. Anthony Lisska considera que Maritain es la persona que más influyó en la difusión del tomismo en el ámbito de la ciencia política y moral de Estados Unidos. ${ }^{26}$

Yves Simon (1903-1961) ${ }^{27}$ fue, junto con Maritain, uno de los grandes impulsores del tomismo en Norteamérica. Compartía con él su visión positiva de la democracia liberal. Simon llegó a la Universidad de Notre Dame en $1938 .{ }^{28}$ Condicionado por la ocupación nazi de Francia, permaneció como profesor visitante en Notre Dame, y tras la guerra se instaló en Chicago, en cuya universidad trabajó hasta su muerte en 1975. Fue uno de los grandes defensores del iusnaturalismo tomista. Su pequeño libro The Tradition of Natural Law (1965) permanece como una obra clásica sobre la fundamentación de la ley en la naturaleza del hombre. ${ }^{29}$

Por la influencia que ha tenido en los paises iberoamericanos, no podemos dejar de hacer una referencia al profesor de Princeton, Paul Sigmund (1929-2014). A lo largo de sus escritos, además de analizar el pensamiento de Santo Tomás sobre la ley natural en el contexto de la ciencia política de Occidente, estudia a fondo las relaciones entre filosofia politica latinoamericana y la ley natural. Entre sus obras sobresale St. Thomas Aquinas on Politics and Ethics. ${ }^{30}$ En su ensayo "Law and Politics" destaca la importancia del pensamiento político y jurídico de Santo Tomás porque,

26 "In twentieth-century neo-scholasticism, Maritain probably contributed more to make Aquinas's moral and political concepts known than any other philosopher or legal scholar whose works were either written or translated into English". Anthony Liska, Aquinas's Theory of Natural Law: An Analytic Reconstruction, Oxford, Clarendon Press, 1998 (cito de la version Kindle, pos. 482).

27 Yves René Marie Simon (1903-1961), nació en Cherbourg, Francia. Estudió filosofía en la Sorbona y en la Universidad católica de París, donde conoció a Maritain.

28 Ese mismo año, 1938, llegaron dos alemanes especialmente relevantes en la filosofia del derecho: Heinrich Rommen y Leo Strauss. Y un año después llegaría Hannah Arendt. Strauss y Arendt fueron contratados por la New School for Social Research (New York). Los norteamericanos pronto reconocieron la extraordinaria valía de estos intelectuales, e introdujeron un nuevo aire en los departamentos de ciencia política, hasta entonces imbuidos de positivísimo y behaviorismo. En los años cuarenta y cincuenta podemos, por tanto, localizar tres focos de resurgimiento del iusnaturalismo en Estados Unidos: la Universidad de Notre Dame, la Universidad de Chicago y la New School for Social Research (New York).

29 Yves Simon, The Tradition of Natural Law: A Philosopher's Reflections, [1965], New York, Fordham University Press, 1999.

30 Paul Sigmund, St. Thomas Aquinas on Politics and Ethics, New York, Norton \& Co Inc, 1988. Esta obra no es solo una selección de textos de Santo Tomás sobre cuestiones éticas y políticas, sino también un análisis del trasfondo teológico, epistemológico y filosófico del pensamiento del Aquinate. A lo largo del libro las notas al pie explican los términos técnicos y las referencias históricas, bíblicas y clásicas. Dentro del apartado "Backgrounds and Sources" desarrolla cada pasaje de Santo Tomás con selección de textos de Aristóteles, San Agustín y Dionisio Aeropagita. En el apartado "Interpretations" muestra el impacto de Santo Tomás sobre el pensamiento medieval, el Renacimiento, y en el pensamiento político posterior hasta nuestros días, incluidas las democracias cristianas en Europa y Latinoamérica. La última parte contiene ocho estudios sobre la influencia del tomismo en los actuales debates sobre la guerra, la contracepción y el aborto. 
... apoyándose [el Aquinate] en Aristóteles, reafirma el valor de la política para justificar que tanto la ciencia como la vida politica son actividades moralmente positivas, por cuanto enlazan con el plan de Dios para los hombres [...] [Santo Tomás] Desarrolla una teoría de la ley natural coherente y lógicamente integrada, que sigue siendo una fuente importante de las normas jurídicas y morales. Estos logros han llegado a formar parte del patrimonio intelectual de Occidente, y han inspirado filósofos del derecho y movimientos sociales y religiosos hasta nuestros dias. ${ }^{31}$

Heinrich Albert Rommen (1897-1967) llega a Estados Unidos, procedente de Alemania, en 1938, gracias a la mediación del Comité Episcopal Americano para los Refugiados Católicos. Comenzó trabajando en la Universidad de San José (19381946), continuó su docencia en la Universidad de Santo Tomás (1946-1953), y terminó sus dias como profesor en Georgetown University (1953-1947). Rommen es conocido en Estados Unidos principalmente por ser el autor de The State in Catholic Thought: A Treatise in Political Philosophy (1945) ${ }^{32}$ y The Natural Law (1947). ${ }^{33}$ Ambos libros fueron escritos en Alemania antes de que tuviera que emigrar a Estados Unidos a consecuencia de la persecución nazi.

La cuestión central que se plantea Rommen en Natural Law es: ¿por qué obligan las leyes?, ¿dónde se encuentra la fundamentación ética del poder coactivo del Estado? Y explica que las respuestas gravitan en torno a dos polos: los que dan primacía a la razón sobre la voluntad en la génesis de la norma (lex-ratio position) y los que dan la primacía a la voluntad sobre la razón (lex-voluntas position). La primera defiende que el conocimiento de lo que debe hacerse viene primero; la fuerza que ejecuta ese juicio viene después (de la directiva de la razón). Por ejemplo, cuando decimos que la fuerza debe estar justificada por la ley, reconocemos al menos implícitamente que la ley y la fuerza no son lo mismo. Una cosa es decir que la fuerza sin ley está injustificada, y otra muy distinta que la ley es fuerza. La tradición de la lex-voluntas sostiene que la ley obliga en virtud del poder superior o voluntad de la autoridad política; la voluntad va primero, y la razón detrás, para dirigir la aplicación del mandato. Desde esta perspectiva, la ley y la libertad están enfrentadas, porque el movimiento libre de un individuo solo puede ser rectificado por la voluntad de otro. Sin embargo, para la tradición de la lex-ratio, la ley y la libertad no están necesariamente enfrentadas, porque ambas se fundamentan en la misma raíz: la medida racional de la acción. Rommen defiende la supremacía de la lex-ratio, porque únicamente sobre el fundamento de la primacía de la razón tiene sentido la ley como obligación. La Ilustración, incluido el mismo Locke, siguió generalmente la filosofía de la lex-voluntas.

31 Paul Sigmund, "Law and politics", en Kretzmann, N. y Stump, L. (eds.), The Cambridge Companion to Aquinas, New York, Cambridge University Press, 1993, p. 217.

32 Heinrich Rommen, The State in Cahtolic Thought, A Treatise in Political Philosophy, St. Louis (MI), Herder, 1945.

33 El libro Natural Law, de Rommen, fue originalmente publicado en alemán en 1936, pero la edición inglesa no es una mera traducción, sino una ampliación de la obra; además, los editores se han preocupado por añadir a pie de página las referencias bibliográficas de cada autor citado por Rommen. En 1998 fue reeditado con una larga introducción de Russell Hittinger en la que nos muestra el panorama del pensamiento filosófico americano de los años cuarenta y cincuenta, y una visión de conjunto del resurgir del iusnaturalismo norteamericano. 
Todos los autores que acabamos de referir compartian la convicción de que la metafisica tradicional de la ley natural podia defenderse sin necesidad de adoptar la postura antimodernista sobre las instituciones politicas.

Tal y como Rommen plantea la cuestión en The State in Catholic Thought, se debe rechazar la reacción romántica contra la modernidad, una reacción que llevó a muchos apologistas católicos del siglo XIX a reivindicar la restauración de los tronos perdidos y el apoyo de los que se mantenían. Desde semejante postura, la ley natural degeneraría en una ideología que aspira a identificar contingentes formas sociales y políticas con cuestiones fundamentales de orden metafísico. Quizá el mayor mérito de estos autores sea el de haber separado la doctrina tradicional sobre la ley natural, de la reacción conservadora del XIX contra las democracias constitucionales nacidas de la revolución. ${ }^{34}$

Como dice Hittinger, "el advenimiento del movimiento intelectual conservador en Estados Unidos seria incomprensible sin estos europeos”. ${ }^{35}$

\section{JOHN COURTNEY MURRAY: EL PATRIOTISMO IUSNATURALISTA}

Mención aparte merece John Courtney Murray (1904-1967), teólogo jesuita norteamericano, por su libro We hold these truths (1960). ${ }^{36}$ Se trata de una colección de ensayos de filosofía política en los que estudia las dos grandes tradiciones de iusnaturalismo (a las que nos hemos referido al principio de este trabajo) en relación con el origen de Estados Unidos de América. ${ }^{37}$

Los presupuestos del pensamiento de Murray sobre ley natural los podemos resumir en cuatro puntos. Primero, su realismo epistemológico, donde el entendimiento humano es medido por las cosas, y no al revés. Segundo, una naturaleza comprendida como realidad teleológica, donde la forma de cada ser es su "causa final". Tercero, una teología natural, que reconoce la existencia de Dios, razón eterna, situado en la cumbre del orden del ser, cuya voluntad es que el orden de la naturaleza se realice en todas sus dimensiones. Y finalmente, una moral como prolongación del orden metafísico en la dimensión de la libertad humana, o, con otras palabras, una libertad relacionada con un orden de la naturaleza que no se impone ciegamente sobre la voluntad humana, sino que se le presenta como objeto de colaboración y de respeto.

34 Russell Hittinger, Introducción al libro de Rommen, Natural Law, Indianapolis (Indiana), Liberty Fund Inc., 1998 (cito de la versión para Kindle, pos. 109).

35 Ibid., pos. 297.

36 John C. Murray, We Hold these truths (1960), Maryland, Sheed \& Ward, Lanham 2005.

37 En castellano hay publicado un estudio detallado del pensamiento de Murray, realizado por el ahora rector de la Universidad Pontificia de Comillas, el profesor Julio Luis MARTínez S.J., Consenso público y moral social: las relaciones entre catolicismo y liberalismo en la obra de John Courtney Murray, Madrid, Univ. Pontificia de Comillas, 2002. Salvo esta noble excepción, es llamativo que el pensamiento de Murray sea hasta ahora tan poco conocido en el ámbito de la cultura hispana. En el Congreso Mundial de Filosofía del Derecho de 2015, en Washington, presenté una comunicación sobre el "Iusnaturalismo en el pensamiento de Murray", pendiente de publicación. 
Murray explica que la doctrina clásica de la ley natural reconoce un orden de derechos que no son anteriores a la comunidad, sino que se dan con el mismo conformarse de la comunidad. La ley natural es la que constiuye al hombre en miembro de la comunidad. O mejor dicho, la ley natural es la expresión de la correcta integración del hombre en la comunidad. Según Murray, la doctrina clásica de la ley natural no proporciona, al menos en primer término, una filosofia de los derechos humanos, en el sentido de derechos subjetivos o poderes frente al Estado, como lo hace el iusnaturalismo de la modernidad. El hombre se comprende como miembro de un orden instituido por Dios y sometido a las leyes que lo consitituyen en dicho orden. Desde esta perspectiva, las leyes objetivas tienen la primacía sobre los derechos subjetivos. Así se entiende la afirmación de $\mathrm{Mu}-$ rray de que la doctrina de la ley natural es una filosofia del derecho (no de los derechos), por cuanto expresa un orden social. De este modo, la reflexión sobre la ley natural no surge, como decía Locke, de la consideración de un ser humano abstracto, aislado, desde el cual deduce sus derechos como individuo. Las leyes humanas serán justas y verdaderamente democráticas, no tanto porque sean expresión de la voluntad mayoritaria, sino porque son expresión de un orden social natural del que todos participan.

Murray nos muestra que la ley natural no es primariamente la expresión de un conjunto de prerrogativas o libertades individuales frente al Estado, que éste viene de algún modo a proteger (y también limitar) con sus normas. La ley natural es en primer término la expresión de la correcta integración del hombre en la comunidad. Dicho de otro modo: por la ley natural el hombre se dispone de manera adecuada en la comunidad de la que naturalmente forma parte.

Por esta razón, la ley (toda ley, también la ley positiva) no es un obstáculo a la libertad del hombre, sino un instrumento con función educadora de la voluntad humana en la búsqueda del bien común, y como consecuencia, de su perfección personal. En el iusnaturalismo de Murray, igual que en Santo Tomás, la perfección personal es esencialmente disposición hacia el bien común. Esto se explica porque la perfección de algo o de alguien que es parte de un todo hay que apreciarla por la relación que guarda con el todo del que forma parte. ${ }^{38}$

\section{LOS "ARISTOTÉLICOS". CAMBIO DE FOCO: DE LAS NORMAS A LAS VIRTUDES}

Los autores a los que nos hemos referido en los dos apartados precedentes irrumpen en el pensamiento americano en cierta manera como agentes extraños en un contexto mayoritariamente utilitarista y analítico, dominante en Estados Unidos. Pero junto a ellos, en la segunda mitad del siglo XX, surgen en el contexto de la

38 "Por eso dice San Agustín en III Confes. que es deforme cualquier parte que no se armoniza con el todo. De aquí que, al ser todo hombre parte de un Estado, es imposible que sea bueno si no vive en consonancia con el bien común, y, a la vez, el todo no puede subsistir si no consta de partes bien proporcionadas. En consecuencia, es imposible alcanzar el bien común del Estado si los ciudadanos no son virtuosos" (ST.I-II: q. 92, a.1, ad.3). 
filosofia analítica una serie de autores que cambiarán el foco de la filosofia moral dominante: desde las normas hacia las virtudes. Aun sin ser propiamente tomistas, abonarán el terreno para un renacimiento tomista que se verificará en el tránsito del siglo XX al XXI, y que poco a poco va ganando protagonismo en el contexto de la filosofia ética, política y jurídica de Estados Unidos.

Entre estos autores destacan Elizabeth Anscombe, Alasdair MacIntyre y Martha Nussbaum. Consideración aparte merece John Finnis, porque aunque surge también en el contexto de la filosofia analítica, lo enmarcamos en el apartado siguiente sobre los neoclásicos.

Elizabeth Anscombe (1919-2001), discipula de Wittgenstein, en su célebre artículo "Modern moral philosophy", ${ }^{39}$ denuncia la carencia de una adecuada filosofia psicológica en la filosofía moderna. Los conceptos de obligación y deber moral, desarrollados de una manera más o menos homogénea desde el siglo XVII, son tributarios de una filosofia que ya no se sostiene. Anscombe reclama una nueva atención de la filosofia moral hacia la teoría aristotélica de la acción, cuyos conceptos clave (virtud, acción intencional, razón práctica...) han sido descuidadas por la filosofia angloamericana desde principio de siglo XX. Se trata de un escrito pionero, que anuncia lo que luego vendrá. En definitiva, Anscombe puso en cuestión toda la filosofia moral analítica de su tiempo y tuvo una influencia decisiva en la obra de Alasdair MacIntyre.

Lo que propuso Elizabeth Anscombe, lo llevó a término Macintyre (nac. 1929). En 1981 publicó After Virtue ${ }^{40}$ un libro decisivo que cambiaría el rumbo de la filosofia moral angloamericana. No fue solo una critica de las teorias éticas posilustradas, sino, sobre todo, un llamamiento hacia la "vía de Aristóteles". No es exagerado afirmar que las obras de MacIntyre y de Anscombe lograron que volvieran al centro del debate, especialmente entre los analíticos, los conceptos de razón práctica y de virtud.

MacIntyre denuncia que las reflexiones de Hume y Kant sobre la razón práctica malograron el sentido originario que Aristóteles dio a esa expresión. Para Aristóteles, la razón práctica no es un mero uso de la razón especulativa aplicada a casos concretos. La razón práctica es una actividad estructuralmente diferente de la razón especulativa (cada una tiene sus propios principios y su propia forma de desarrollo).

MacIntyre explica de qué modo, una vez desintegrada la sintesis medieval, los conceptos filosóficos morales, como restos de un naufragio, cobraron sentidos diversos, muchas veces incompatibles entre sí, y a la postre las nociones de virtud moral y racionalidad práctica se hicieron incomprensibles. Desde Kant se habían multiplicado las teorias normativistas, que se centraron en la norma que hay que obedecer, en lugar de en la virtud que hay que adquirir. 
Pero desde la perspectiva del sujeto agente, la idea de virtud y de razón práctica necesitaban un fundamento ontológico, o al menos una psicologia filosófica, cuya ausencia fue precisamente lo que Anscombe denunció, y que MacIntyre no termina de proporcionar. Pues, le guste o no, la filosofía moral aristotélico-tomista se fundamenta en una concepción metafísica de la naturaleza humana.

MacIntyre, al mismo tiempo que critica duramente el ideal ilustrado de una racionalidad desligada de las tradiciones, hace una propuesta audaz que combina lo mejor de las tradiciones rivales de la ética, con un talante que nos recuerda a Santo Tomás, el cual recoge lo mejor de cada uno para ofrecer con un lenguaje moderno una alternativa al pensamiento liberal.

La filósofa norteamericana Martha Nussbaum, nacida en Nueva York en 1947, profesora primero en Harvard y luego Brown University (Rhode Island), ha contribuido a la difusión del aristotelismo en Estados Unidos, especialmente en lo que se refiere a la teoría del conocimiento práctico. Sus estudios de la phronesis en Love's Knowledge (1990) ${ }^{41}$ combinan la filosofía griega y la literatura contemporánea, con especial atención a las obras de Henry James. ${ }^{42}$ En The Fragility of Goodness (1986) ${ }^{43}$ además de enseñar cómo los factores externos, ajenos a la voluntad, moldean el propio carácter, reclama la atención hacia lo particular y subraya el papel de las emociones en la formación del juicio ético, en contraste con el formalismo kantiano. En una línea similar a la de MacIntyre, y en cierta manera también a la de Henry Veatch, critica duramente la filosofia moral kantiana. Nussbaum enseña que la imaginación literaria ayuda a desarrollar la capacidad de juicio ético, y la pone en relación con la estructura del conocimiento práctico desarrollado por Aristóteles. En definitiva, Nussbaum critica la ética de normas, y afirma una ética basada en el carácter y nos recuerda el pensamiento de Aristóteles sobre la función de las emociones en la toma de decisiones. Para Nussbaum, la pregunta fundamental en la ética no es "qué normas debo respetar", sino "qué clase de vida merece la pena vivir": este habría de ser el punto de arranque de una filosofia moral. Esta autora, con un estilo fácil y ameno, contribuye a hacer amable al gran público las categorias básicas de la filosofía moral aristotélica.

\section{LOS "NEOCLÁSICOS":}

\section{LA NEW Natural LAW THEORY}

Germain Grisez (1929-) es el fundador de la nueva teoría del derecho natural (NNLT), que algunos califican también como "neoclásica". En el ámbito de la filosofia jurídica sus seguidores más destacados son John Finnis y Robert George, y en un segundo nivel, destacan Joseph Boyle, Gerard V. Bradley, E. Christian Brugger, 
Basil Cole, O.P., Robert G. Kennedy, Patrick Lee, William E. May, Peter F. Ryan, S.J., Russell Shaw, Christopher Olaf Tollefsen, Olaf P. Tollefsen y Robert Matava. Por la importancia que tiene en el iusnaturalismo norteamericano y por la influencia que su trayectoria vital ejerce sobre su pensamiento, vale la pena conocer con un poco de detalle su biografia. ${ }^{44}$ Germain Grisez nace en 1929 en Estados Unidos, en el seno de una familia modesta y católica. Realiza sus estudios de grado en Cleveland's John Carroll University (1947-50), dirigida por los jesuitas, donde conoce a Marshall Boarman, discípulo de Etienne Gilson en Toronto, que lo convierte en un ferviente tomista. La lectura de Santo Tomás le mueve a decidirse por la enseñanza de la filosofia. Con este fin decide realizar sus estudios de Master of Arts (1950-51) con los dominicos de River Forest (Illinois). En 1951 se traslada a la Universidad de Chicago para hacer el doctorado (1951-57), que realiza bajo la dirección de Richard McKeon, experto en filosofia antigua y medieval. Su tesis doctoral, defendida en 1959, es un estudio comparativo de la lógica de Aristóteles (Las súmulas, compendio de lógica aristotélica realizado por el dominico Pedro Hispano en el siglo XIII) con la de Guillermo de Ockham. En 1957, Georgetown University le ofrece la posibilidad de enseñar filosofia moral, y comienza con dos cursos: uno de ética tomista, y otro sobre la ética de Aristóteles y Kant. Durante ese periodo también estudia a fondo la filosofía moral de autores protestantes, y entabla relación con Paul Ramsey, metodista, a la sazón filósofo moral en Princeton. Fue entonces cuando Grisez comenzó a sentar las bases de su peculiar filosofia moral.

Grisez pensaba que, puesto que Santo Tomás estaba principalmente interesado en teología y que en el siglo XIII los argumentos estrictamente filosóficos (sin el concurso de la fe) no estaban muy elaborados, el Aquinate carecía de una filosofia moral coherente y completa, y por tanto insuficiente para "argumentar sobre cuestiones actuales y enfrentarse a argumentos planteados en los tiempos modernos". Pero, al mismo tiempo, consideraba que la filosofia moral posterior era todavía menos viable y menos sólida que la de Santo Tomás. Grisez se siente llamado a completar este vacío. Él conocía a fondo el utilitarismo de Bentham y Mill, que enseñaba en sus lecciones de grado en Georgetown, y pensaba que el utilitarismo implicaba un determinismo psicológico. "Lo que tú eliges está determinado por lo que más te atrae" y, por tanto, no hay propiamente libertad de elección. Y este es precisamente el germen de su filosofia: "En realidad una alternativa no es en términos absolutos mejor ni más atractiva que otra, de lo contrario no habría libertad. La cuestión es que ambas alternativas son más atractivas en diferentes aspectos, porque interpelan de modo diferente las diversas dimensiones de la realización humana”.

Al mismo tiempo que hacía estas reflexiones, a comienzos de los años sesenta surge en el seno de la Iglesia católica el debate sobre la contracepción, en el que Grisez se implicó a fondo. En un principio, Grisez pensó que la contracepción no

44 Sobre la biografia intelectual de Grisez, cfr. Russell SHAw, "The making of the moral theologian", en The Catholic World Report, March 1996, Syracuse, NY, en http://www.ewtn.com/library/homelibr/grisez.txt, y tambiēn cfr. la web de Grisez, http://www.twotlj.org/grisez_collaborators.html. 
era siempre inmoral, pero esto chocaba con la enseñanza tradicional de la Iglesia, expresamente recogida en Casti Connubii de Pio XI. ¿Cómo podía un filósofo moral apoyar esta doctrina? Reflexionando sobre estas cuestiones dibujó un diagrama que representaba los diferentes aspectos de la realización humana (su famosa lista de bienes humanos básicos). La versión más elaborada de su doctrina sobre los bienes humanos básicos está en el capítulo 5 del primer volumen de The way of the Lord Jesus. ${ }^{45}$ La actitud personal ante estos bienes es crucial para la vida moral. La moral - pensaba Grisez- se basa en la relación entre la elección y la acción ante el bien del hombre. Ser bueno moralmente requiere posicionarse a favor de todos los aspectos de la realización humana. Este es, según Grisez, el presupuesto básico de la moralidad.

En 1965 decide publicar su libro (el primero) sobre la contracepción, en la editorial de William May (Bruce Publishing Company, Milwaukee): Contraception and the Natural Law. El núcleo de su argumentación contiene la esencia de su filosofia moral. Simplificando un poco, el argumento es el siguiente: la elección de interrumpir la concepción natural es contraria al bien humano básico de la procreación, y nunca estará moralmente justificada porque supone dirigir la voluntad contra un bien de la persona, ni siquiera en vista de otro bien. Su argumentación contiene también una dura crítica de los argumentos iusnaturalistas opuestos a la contracepción (especialmente el argumento de que no se puede interrumpir una facultad natural). Su crítica fue muy bien acogida en círculos católicos (John C. Ford S.J, profesor de la Catholic University of America y uno de los moralistas católicos norteamericanos más prestigiosos antes del Concilio Vaticano II, acogió con entusiasmo los argumentos de Grisez. Igualmente, Richard McCormick S.J., que lideraba el frente católico anti-proporcionalista). Russell Shaw, entonces un joven escritor de NC News, le ayudó a popularizar sus argumentos, y publicó con él un resumen del libro en forma de entrevista. ${ }^{46}$ Desde entonces, William May y Russell Shaw se convirtieron en compañeros de viaje de Grisez.

En 1965, Grisez publica en la revista Natural Law Forum (que luego cambia de nombre a The American Journal of Jusprudence), "The first principle of practical reason: A commentary on the Summa Theologiae, I-II, Q. 94, A. 2", reeditada en numerosas publicaciones, un artículo en el que critica lo que considera la interpretación neoescolástica de Santo Tomás, según la cual las normas morales se derivan de un conocimiento previo de la naturaleza humana. Finnis reconoce que la lectura de este artículo marcó un punto de inflexión en su pensamiento, que desarrolló luego en su Natural Law and Natural Rights.

Durante los años de docencia en Georgetown (1957-72), Grisez tuvo como uno de sus mejores alumnos a Joseph Boyle, que desde entonces hasta la fecha se convirtió en su principal colaborador.

45 En http://www.twotlj.org/G-1-5-N.html.

46 Germain Grisez, Beyond the New Morality: The Responsibilities of Freedom, Notre Dame, Notre Dame University Press, 1974. 
En 1972, Grisez deja Georgetwon (llevaba ya 15 años), y comienza a enseñar en Campion College, también de los jesuitas, que forma parte de la University of Regina, en Saskatchewan, Canadá. Desde ahí, durante siete años (desde el 1972 hasta 1979), continúa con el desarrollo de su doctrina. Junto con Boyle y Olaf Tollefsen (a quien Grisez dirigió la tesis en Georgetown), publica en 1976 Free Choice: A Self-Referential Argument. Durante su época de Campion, Grisez también escribe Beyond the New Theism: A Philosophy of Religion, que contiene los principales elementos de su original metafisica. Y con la ayuda de Bolye, completa su trabajo sobre el aborto con Life and Death with Liberty and Justice: A Contribution to the Euthanasia Debate.

Durante los años 1974 y 1975, Grisez es uno de los diecisiete coautores que participan en la redacción de The Teaching of Christ: A Catholic Catechism for Adults. Por este motivo, comienza a trabajar con John Finnis, por aquel entonces investigador de Oxford University College, que ya había leído las obras de Grisez. Los editores del catecismo para adultos proponen a Grisez y a Finnis redactar los cuatro capítulos de ética (que al final redactó Finnis con la colaboración de Grisez, que a su vez supervisó toda la obra). Mientras trabajaba en el catecismo para adultos, Grisez se convence de que la Iglesia necesita una nueva teologia moral, que se tome en serio las indicaciones del Concilio para renovarla. En 1977 empieza a pensar que él mismo estaba llamado a realizarla (en Grisez la conciencia de vocación en su trabajo es muy intensa). Pero Campion College no ofrecía los recursos que se requerian para llevarla a cabo (ni siquiera ofrecía posgrados de teologia, ni tenía una biblioteca teológica suficiente). Por este motivo, el 23 de junio de 1978 consigue entrar en Mount Saint Mary Seminary, donde le dotan la cátedra especial de ética cristiana "Rev. Harry J. Flynn Chair of Christian Ethics".

Desde 1978, hasta su jubilación, Grisez trabaja en Mount Saint Mary, donde escribe los cuatro volúmenes de su gran obra The way of the Lord Jesus, dejando incompleto el cuarto. El primer volumen, "Cristian Moral Principles", redactado junto con Joseph Boyle, y con la ayuda de John Finnis y Russell Shaw, se publica en 1983. En esta obra está contenida su doctrina fundamental sobre la ley natural. En el segundo volumen, "Living Christian Life", al que dedica diez años de estudio (se publica en 1993), trata las virtudes teologales y cardinales, el perdón y el arrepentimiento, el razonamiento moral, la justicia, la dignidad, el valor de la vida, el matrimonio y la sexualidad, el trabajo, la propiedad y la vida política. El tercer volumen "Difficult Moral Questions" ve la luz en 1997. El cuarto volumen, "Clerical and Consecrated Service and Life" se publica incompleto en 2013 en su página web.

En la primavera de 2009, Grisez es nombrado profesor emérito de Mount St. Mary y se le concede el grado honorario de "Doctor of Divinity". En la ceremonia de recepción de tal reconocimiento, Grisez pronuncia un discurso de agradecimiento especialmente significativo, en que expresa el vivo sentido de misión con el que durante tantos años llevó a cabo su labor académica.

La NNLT acepta la crítica de la imposibilidad de derivar el conocimiento del deber ser a partir del ser, es decir, de construir una ética a partir de la metafísica. Esta 
crítica, comúnmente conocida como crítica de la "falacia naturalista", ya fue articulada por Hume, desarrollada por Kant, y planteada de nuevo por Moore. Grisez entiende que el conocimiento del deber moral comienza por los bienes humanos básicos (vida, conocimiento, experiencia estética, armonia con la trascendencia, juego, amistad, racionalidad práctica), que se presentan interpelando directamente a la razón práctica. La naturaleza humana se conoce después, ya que esta es conocida a partir de sus potencias, y sus potencias se conocen por sus actos, y sus actos se conocen por sus objetos, que son los "bienes humanos básicos" evidentes. La NNLT defiende que, en el orden del conocimiento, primero son los bienes humanos básicos.

Este argumento de la falacia naturalista se convierte en arma arrojadiza, especialmente contra los tomistas, porque se les acusa de pretender derivar normas morales a partir del conocimiento de la naturaleza humana. Si a esto le añadimos la negación, por parte de la ciencia moderna, de una teleología impresa en la naturaleza y la negación de la existencia de Dios, el iusnaturalismo tomista se quedaria sin fundamento.

En este contexto es como se entiende la intención fundamental de la teoría de Grisez sobre la ley natural. Él acepta la crítica de falacia naturalista, pero dice que no es aplicable a Santo Tomás. Según el Aquinate, el conocimiento del deber ser no depende, al menos en primera instancia, de un previo conocimiento de Dios, ni tampoco presupone un conocimiento de la teleologia de la naturaleza creada. Fue Suárez - explica Grisez- el que desfiguró el tomismo y el que confundió a la posterioridad al presentar como tomista una ética que no se correspondía con el pensamiento del Aquinate. ${ }^{47}$

Grisez explica que los primeros principios de la ley natural son evidentes por sí mismos. No se conocen deductivamente a partir del conocimiento de la naturaleza humana. Los primeros principios son conocidos inmediatamente, sin premisas intermedias ni deducción alguna. Estos primeros principios interpelan directamente a la razón práctica. Su conocimiento como bienes para el hombre, como bienes humanos, no presupone un previo conocimiento o análisis de las tendencias humanas. Lo cual no significa que dichas tendencias no existan, ni que no exista la naturaleza humana; lo que sucede es que primero conocemos los bienes, y luego, como consecuencia, la naturaleza humana. En esto la NNLT no se aparta

47 John Finnis, Natural Law and Natural Rights, Oxford, Oxford University Press, 1980, cuando critica la imagen de la ley natural como un producto racional derivado del estudio de los hechos (la séptima de las imágenes típicas sobre la ley natural que analiza) no se queda en Suárez, sino que llega hasta Gabriel Vázquez de Belmonte, para denunciar la deformación del iusnaturalismo tomista según la cual las "esencias" de las cosas son las que marcan el contenido de la ley natural. Por su parte, Francisco Carpintero Benítez, catedrático de la Universidad de Cádiz, a quien considero el mejor historiador del iusnaturalismo, desgraciadamente poco conocido en el ámbito angloamericano, demuestra con mucho más detalle que Finnis, el modo en que Gabriel Vázquez de Belmonte y Luis de Molina deformaron el tomismo, al insistir en que la fuente primordial de la moralidad nace del objeto, de la naturaleza misma del acto, y así se terminó presentando el iusnaturalismo tomista como fundamentado en las esencias de las cosas. Cfr. Francisco CARPINTERo, La ley natural, una realidad por explicar, México D.F., Universidad Autónoma de México, 2013, pp. 171-178. 
de Santo Tomás. La novedad, y uno de sus puntos más criticados, quizá exageradamente, es que no reconoce también el recorrido inverso: que los bienes humanos, y por tanto el deber ser, pueda ser mejor conocido a partir del conocimiento de la naturaleza humana. ${ }^{48}$

Con esta tesis de la evidencia de los primeros principios del obrar, Grisez considera innecesario plantearse como premisa moral la teleologia del hombre. En la ética no es necesario considerar previamente la razón de ser o la finalidad de la vida humana. Si aceptáramos que el conocimiento moral tiene que partir de consideraciones (especulativas, no prácticas) sobre el para qué de la existencia humana, nos haríamos acreedores de la crítica de la falacia naturalista, piensa Grisez. Tampoco es necesario plantearse la cuestión de Dios y su relación con la existencia humana para comprender todos los principios de la razón práctica. Los principios son conocidos en sí mismos, de manera inmediata, sin necesidad de apelar a Dios. Los primeros principios de los que habla Grisez no son morales, sino principios del obrar: son "premorales" a partir de los cuales, con unos criterios adicionales ("modos de responsabilidad") formulamos los principios morales. Tanto los delincuentes

48 En este punto hay, sin embargo, una interpretación conciliadora entre Santo Tomás y Grisez, realizada por Stephen L. Brock, cuando comenta la afirmación tomista de que la razón humana aprehende como bueno todo aquello hacia lo cual el hombre tiene una inclinación natural (I.II., q. 94, a.2). La interpretación de Brock salva de alguna manera la pretensión de los neoclásicos de fundamentar el deber ser en un conocimiento inmediato del bien, sin necesidad de apelar en primera instancia a las inclinaciones del hombre, o, mejor dicho, explicando que el conocimiento del bien es en sí mismo una inclinación racional. De este modo, la comprensión natural del bien por parte de la razón no se deriva, como un acto posterior, de la inclinación natural hacia el bien. Sucede más bien al contrario: la inclinación se deriva de la comprensión racional del objeto como bien humano. Brock comparte con los neoclásicos la tesis de que la comprensión de un objeto como bien no es lo mismo que registrar la existencia de un deseo hacia ese bien. Y trae a colación la diferencia entre los bienes honestos y los bienes deleitables. Los bienes honestos son tales, no porque satisfagan una inclinación, sino por sí mismos. Los bienes deleitables, en cambio, son bienes solo porque satisfacen una inclinación. Por otra parte, Brock explica que para Santo Tomás lo primero conocido es el ser (que algo es), acto seguido es la conciencia del conocimiento de esa realidad (que algo es verdadero), y por último el conocimiento de la propia tendencia hacia el objeto (que algo es bueno). Concretamente, en S.T. I, q.16, a.4 ad.2: "Lo primero que aprehende el entendimiento es el mismo ser; lo segundo, que conoce el ser; lo tercero, que apetece el ser. Luego primero se da el concepto de ser; después, el de lo verdadero; por último, el de bien aun cuando este se dé en las cosas". Igualmente, Brock se basa en I, q. 4, a. 1, donde Santo Tomás afirma que "el concepto de bien sigue al ser, en cuanto que de algún modo es perfecto; lo cual lo convierte en apetecible". Y puesto que algo es perfecto solo cuando logra la plenitud de su forma (la plenitud de un contenedor viene determinada por su capacidad, que está determinada por su forma), todo bien es siempre considerado en relación con su forma, lo cual solo capta el entendimiento humano. La razón de perfección está presupuesta en la razón de bien, no al revés. La razón de perfección es la matriz desde la que cada cosa es engendrada. En definitiva, es la captación de la forma lo que atrae al hombre, y eso supone un conocimiento racional. ("The ratio of the perfect is the matrix in which it is begotten and apart from, which it corrupts"). Dicho sea de paso, esta consideración de Brock es especialmente interesante para criticar el planteamiento de Hume. Cfr. Stephen Brock, "Natural inclinations and the intelligibility of the good in thomistic natural law", en Vera Lex VI (1-2) (2005), pp. 57-78. En una línea similar a la de Brock se mueven los argumentos de Robert Matava, que en el Congreso Mundial de Filosofía del Derecho, celebrado en Washington en 2015, realizó una exposición crítica de la recién publicada obra de Steven Jensen, Knowing Natural Law (2105), al que luego nos referiremos, en la que defendía en parte los argumentos de Grisez y Finnis, pero justificaba al mismo tiempo la necesidad de fundar la ley natural también a partir de la naturaleza humana, especialmente en un contexto relativista como el actual, donde la evidencia de los bienes humanos básicos empieza a ser cuestionada. 
como los santos se guían por los primeros principios, si bien los delincuentes no los persiguen moral o responsablemente.

Por otra parte, y este es quizá el punto más débil de la teoría de Grisez, los bienes humanos básicos se consideran últimos, es decir, no están subordinados unos a otros: son inconmensurables, porque no están estructurados entre sí antes de la elección de cada persona. Todos son igualmente importantes. No podemos decir, por ejemplo, que el bien del conocimiento sea mayor que el bien del juego, o que el de la amistad, o que el de la relación con Dios. Solo si los bienes humanos se derivaran de un único fin último, entonces se podrian comparar entre sí por relación a ese fin último. En la NNLT no hay tal fin unificador en virtud del cual los demás sean bienes. ${ }^{49}$

Desde que Grisez planteó su doctrina, y John Finnis la difundió en el ámbito de la filosofia jurídica, el debate entre las diversas interpretaciones de Santo Tomás y el estudio de las relaciones entre la razón especulativa y razón práctica ha progresado bastante, y poco a poco ha quedado claro que en algunos puntos la doctrina de la NNLT se aparta en cuestiones esenciales del pensamiento original del Aquinate.

John Finnis (Adelaide, South Australia, 1940) es, ${ }^{50}$ sin duda, el iusnaturalista más conocido en Estados Unidos, y posiblemente el más prestigioso de nuestro tiempo. Discípulo de Hart, profesor emérito de Filosofia del Derecho en Oxford (donde imparte docencia desde 1996) y en Notre Dame, ha sido el amplificador de la doctrina de Grisez. Su filosofia moral, supuestamente tomista, se inspira principalmente en Germain Grisez, en especial en su ética y en su teoría de la acción. ${ }^{51} \mathrm{Su}$ obra más conocida es Natural Law and Natural Rights, de 1980, en la que se contiene lo esencial de su filosofia jurídica. La obra es una combinación original de filosofía analítica (al estilo de Hart), con la ética de Grisez y la filosofía de Santo Tomás. ${ }^{52}$

49 Especialmente centrado en esta crítica publiqué "Grisez y los primeros principios de la ley natural", en Persona y Derecho 52, pp. 339-393 (disponible en http://dadun.unav.edu/handle/10171/14564)

50 Finnis cursó sus estudios superiores entre las universidades de Adelaida (Australia) y Oxford, donde realizó el doctorado bajo la dirección de H. L. A. Hart. Poco a poco, especialmente por el estudio de las obras de B.J.F. Lonergan y del Card. Newman, en diciembre de 1962 es recibido en la Iglesia católica (inicialmente anglicano, en su juventud, perdió la fe con las lecturas de Bertrand Russell y David Hume). Entre los años 1965 y 1967 trabajó como profesor en la Universidad de Berkeley, California. Es entonces cuando entró en contacto con las obras de Grisez. Al regresar a Oxford, Hart propuso a Finnis el escribir un libro con el título "Natural Law and Natural Rights" para publicar en Clarendon Law Series, fundada por Hart (que se hizo precisamente famosa por el libro The Concept of Law, publicado por Hart en 1961). Finnis ha colaborado activamente con la Santa Sede, formando parte de la Comisión Teológica Internacional.

51 El mismo Finnis reconoce que la lectura del artículo "The first principle of practical reason", escrito por Grisez en 1967, supuso para él una conversión intelectual. Hice la traducción al castellano en la revista Persona y Derecho, 2005, editada por la Universidad de Navarra, en http://www.twotlj. org/EthicalTheory.html. Sería un error pensar que Finnis es un mero continuador de Grisez: aporta consideraciones originales sobre la justicia, el derecho, el orden político y el bien común, y una

construcción que difiere de Grisez a la hora de construir las normas de comportamiento a partir de
los bienes humanos básicos.
52 John Finnis, Natural Law and Natural Rights, Oxford, Oxford University Press (Clarendon Law Se-

construcción que difiere de Grisez a la hora de construir las normas de comportamiento a partir de
los bienes humanos básicos.
52 John Finnis, Natural Law and Natural Rights, Oxford, Oxford University Press (Clarendon Law Series), 1980. 
Más tarde publica Fundamentals of Ethics, ${ }^{53}$ una breve obra en la que defiende la objetividad y verdad de los principios morales y contiene una critica del utilitarismo ético, así como de los principios de la ética kantiana. En dicho libro, más destinado a moralistas que a filósofos del derecho, trata sobre el conocimiento de la ley natural a partir del estudio de los "bienes humanos básicos", objetos de la razón práctica. Pone de relieve el concepto central de actividad racional humana, frente a la reducción de la moral a mero deseo y a la disolución del bien moral real en bienes aparentes (utilidad, placer, etc.).

En su obra Aquinas hace una exposición del pensamiento ético jurídico de Santo Tomás tratando de ajustarlo a los moldes de la filosofia moral de Grisez. ${ }^{54}$

En 2011, Oxford University Press publicó Collected Essays of John Finnis, en cinco tomos, con ciento seis ensayos seleccionados por Finnis entre sus estudios filosóficos y teológicos, con una introducción suya a cada uno de los tomos. Estos ensayos están agrupados en torno a los siguientes temas: razón práctica, intención e identidad, justicia y otros problemas morales, ley y teoría legal, y revelación cristiana y razón pública. En 2013, la misma editorial publicó Morality and Law: the Philosophy of John Finnis, editada por dos de sus discipulos: John Kewon y Robert George, con aportaciones de veintisiete autores, profesores, colegas, antiguos discípulos, y críticas y respuestas de Finnis a cada una de ellas (en 125 páginas del total de las 600 que tiene el libro). La disposición de esta obra sigue el esquema de los cinco grandes temas referidos. Comienza con un ensayo de Joseph Raz sobre la teoría del valor, y termina con un ensayo de Grisez sobre la articulación entre el fin último y el primer principio moral.

Entre los discípulos de Finnis y colaboradores de Grisez, destaca Robert George (nac. 1955, Morgantown, West Virginia, Estados Unidos). George es un académico comprometido con la vida política. ${ }^{55}$ En Harvard realizó sus estudios de máster

53 John FinNis, Fundamentals of Ethics, Georgetown University Press, 1983.

54 John Finnis, Aquinas: Moral, Political, and Legal Theory, Oxford, Oxford University Press, 1998.

55 Desde sus años de estudiante universitario, Robert George participó activamente en el partido Demócrata y en diversas iniciativas de promoción social de las clases menos favorecidas. Hacia finales de los años ochenta, desengañado por las políticas sociales demócratas, especialmente las relativas a la vida humana y a la protección de la familia, abandonó el partido. En 1989 fue nombrado letrado del juez del Tribunal Supremo, William H. Rehnquist. En 1993 fue nombrado por el presidente de Estados Unidos miembro de la Comisión de los derechos civiles (United States Commission on Civil Rights), cargo que desempeñó hasta 1999. Durante ese periodo se destacó por dirigir el estudio sobre la inconstitucionalidad de la restricción de la libertad religiosa en las escuelas públicas de los Estados Unidos. Desde 2002 hasta 2009 fue miembro del Consejo del Presidente sobre cuestiones bioéticas. Influyó con su trabajo en las decisiones del Gobierno sobre el tratamiento de los embriones y la regulación de la clonación humana. George es miembro del consejo editorial de prestigiosas revistas, entre las que destacan Touchstone, First Things (publicación periódica, sobre la que luego nos detendremos), Public Discurse, The American Journal of Jurisprudence, Journal of Law, Philosophy, and Culture. Actualmente es el editor general de la colección New Forum Books, de Princeton University Press. Es miembro de consejos de administración de diversas instituciones: Lynde and Harry Bradley Foundation, The Ethics and Public Policy Center, The Institute for American Values, The Institute on Religion and Democracy, The Center for Individual Rights, The Family Research Council, y The Culture of Life Foundation. Es el fundador de la American Principles Project, una organización política de apoyo a la vida y a la familia. Es cofundador y presidente del consejo de administración de la Organización Nacional para el Matrimonio (National 
en Derecho y Teología. Realizó su doctorado en Oxford bajo la dirección de John Finnis, con una tesis sobre la ley natural y la exigencia legal de las obligaciones morales. En su tesis criticaba el pensamiento de Grisez como "excesivamente libertario”, pero con el tiempo y su relación con Grisez, fue comprendiendo, asumiendo y defendiendo la filosofia del propio Grisez en numerosas publicaciones conjuntas. En 1985 comenzó a enseñar, en Princeton, Filosofia del Derecho y Derecho Constitucional. En 1999 fue designado en dicha universidad como McCormick Professor of Jurisprudence. El New York Times lo consideró en 2009 como el intelectual cristiano conservador más influyente de Estados Unidos. ${ }^{56}$

Tuve la ocasión de estar con Robert George durante una semana en Valencia en el 2004, en un curso dirigido por él, organizado por la Universidad Menéndez Pelayo, en el cual le ayudaba como traductor simultáneo. Soy testigo, no solo de su agudeza intelectual, sino también de su extraordinaria amabilidad. Sin embargo, creo que, al menos desde el punto de vista de los fundamentos, George no es un pensador original ni tiene una doctrina sistemática de factura propia. Sus publicaciones son en su mayoría colecciones de artículos que tratan de resolver problemas sociales o políticos, en los que razona casi siempre con los argumentos basados en la filosofia original de Grisez: en defensa de toda vida humana contra el aborto o la manipulación de embriones; defensa de la familia frente a la equiparación del matrimonio heterosexual y homosexual; defensa de libertad en la educación, y oposición a la imposición de la ideología de género en la educación... ${ }^{57}$

En general, George añade una última concreción al pensamiento de Grisez y Finnis, apostando decididamente por llevarlo a la realidad mediante propuestas politicas concretas. Simplificando mucho, podriamos decir que Grisez pone los fundamentos filosóficos y teológicos de este movimiento; Finnis los proyecta sobre el ámbito filosófico jurídico; y George trata de que se traduzcan en proyectos políticos y jurídicos concretos. Estos autores son para mí como una trilogia, que va de lo más general a lo más concreto.

\section{LOS "NEOESCOLÁSTICOS"}

Frente a los autores de la NNLT se ha desarrollado en Estados Unidos una doctrina sobre la ley natural, que se considera más fiel a Santo Tomás.

La autoridad de Henry Veatch (1911-1999) —fue presidente de la American Philosophical Association (Western Division), así como de la American Catholic Philosophical Association- y su crítica a las teorias que trataban de fundamentar el

Organization for Marriage). Es miembro del Council on Foreign Relations y es el Herbert W. Vaughan Senior Fellow del Witherspoon Institute. Es consejero (Of Counsel) del despacho jurídico Robinson \& McElwee. Representó a la Madre Teresa en su petición al Tribunal Supremo de la revocación de la doctrina proabortista de la sentencia Roe v. Wade. En diciembre de 2008, el presidente de Estados Unidos le impuso la Presidential Citizens Medal, uno de los más grandes honores que un civil puede recibir del Gobierno norteamericano.

56 Véase http://goo.gl/aqXfYM.

57 Sobre las obras de Robert P. George, consultar: http://www.bioeticawiki.com/Robert_P_George 
conocimiento de la ley moral prescindiendo de la metafísica, entre las que incluía la NNLT y la filosofia de MacIntyre, influyó en el pensamiento de autores tomistas como Russell Hittinger, Ralph McInerny, Steven Long y Steven Jensen, que critican los planteamientos de Grisez y Finnis.

Veatch reclama la necesidad de un renovado estudio de la metafísica o de la "filosofia natural" para fundamentar la ética, y considera que la filosofia moral de Santo Tomás es incomprensible sin la vía ontológica. Comenzando con su crítica a la apología del existencialismo de William Barrets en su Irrational Man, ${ }^{58}$ a la que responde con su antitesis Rational Man, ${ }^{59}$ y siguiendo con sus dos criticas a la ética contemporánea (For an Ontology of Morals ${ }^{60}$ y Human Rights: Fact or Fancy?), ${ }^{61}$ Veatch nos presenta una filosofia moral basada en la teoría de la acción expuesta por Aristóteles y desarrollada por Santo Tomás. En Swimming Against the Current in Contemporary Philosophy, Veatch reconoce su propósito de rehabilitar a Aristóteles y Aquino como filósofos contemporáneos. ${ }^{62}$ Según Veatch, la necesidad más apremiante de la ética debería ser, no tanto una filosofia del lenguaje, ni una lógica para la ética, ni tampoco una fenomenología, sino una ontología moral. ${ }^{63}$

Por su parte, Ralph McInerny (1929-2010), desde la Universidad de Notre Dame, es uno de los tomistas norteamericanos que más ha contribuido a la rehabilitación del iusnaturalismo clásico en Estados Unidos. En su Ethica Thomistica ${ }^{64}$ explica su concepción de la ley natural y de la razón práctica. Se trata de un pequeño libro, original en la forma y fácil de leer (escrito con ejemplos de la vida real, que ilustran cada uno de sus argumentos), donde el autor defiende el fundamento ontológico de la ética de Santo Tomás. Contiene una crítica al argumento de la "falacia naturalista" dirigida contra el tomismo. En 1992 publica Aquinas on Human Action: A Theory of Practice, ${ }^{65}$ un análisis de la filosofía práctica de santo Tomás, donde muestra la necesidad de comprender la ley natural en relación con la teoría tomista de la acción humana, que a su vez enlaza con la providencia divina (critica la tesis de R. Gauthier según la cual Santo Tomás vició la filosofia original aristotélica al mezclarla con sus reflexiones sobre la providencia divina). Y en su A First Glance of St. Thomas Aquinas ${ }^{66}$ nos muestra las diferencias entre la filosofia moral de Santo Tomás y la que arranca con Descartes y se proyecta sobre la "modernidad" hasta nuestros dias.

58 William Barrett, Irrational Man: A Study in Existential Philosophy, New York, Anchor Books, 1956.

59 Henry Veatch, Rational Man (1962), Indianapolis (Indiana), Liberty Fund Inc., 2003.

60 Henry Vеaтch, For an Ontology of Morals, Evasnston (Illinois), Northwestern University Press, 1971.

61 Henry Veatch, Human Rights: Fact or Fancy?, Baton Rouge (Louisiana), Louisiana State University Press, 1985.

62 Henry Vеatch, Swimming Against the Current in Contemporary Philosophy, Washington D.C., Catholic University of America Press, 1990.

63 Ibid., p. 156.

64 Ralph McInerny, Ethica Thomistica, Washington D.C., Catholic University of America Press, 1982.

65 Ralph McInerny, Aquinas on Human Action: A Theory of Practice, Washington D.C., Catholic University of America Press, 1992.

66 Ralph McInerny, A First Glance of St. Thomas Aquinas, Notre Dame (Indiana), University of Notre Dame Press, 1990. 
Russell Hittinger (nac. 1949), director del departamento de filosofía y religión en Tulsa University (Oklahoma), es quizá el más conocido entre los críticos de la línea de Finnis/Grisez. La mayor parte de sus publicaciones versan sobre cuestiones éticas, que aborda desde tres perspectivas que se entrecruzan: filosófica, teológica y jurídica. Sus dos obras más importantes sobre la ley natural son: The First Grace: Rediscovering Natural Law in a Post-Christian Age ${ }^{67}$ una colección de ensayos sobre la ley natural; y A Critique of the New Natural Law Theory, ${ }^{68}$ dirigida contra el iusnaturalismo de Finnis y Grisez.

Para Hittinger, la ley natural no se puede comprender cabalmente cuando se separa de la idea de la providencia divina. Hittinger explica que el iusnaturalismo ha florecido en el jardín de la teologia, y está profundamente enraizado en la doctrina de la creación y de la providencia. Una ley para el hombre que crea el propio hombre no es propiamente una ley natural. Hittinger se propone reorientar la comprensión de la ley natural hacia la idea de autoridad y de legislador, es decir, reclama la consideración de un creador de la naturaleza. Los hombres somos criaturas: la naturaleza es un don, no un producto del ingenio humano. Nuestras inclinaciones y nuestro propio intelecto son signos de la ley de Dios, pero no son ellas mismas la ley. Si tratamos de aislar la ley natural de su fundamento teológico, seremos incapaces de comprender la ley natural como ley, pero también de justificar la obligatoriedad de los primeros principios derivados de la naturaleza. Las inclinaciones no serán más que puros hechos que hay que soportar o, si es posible, evitar.

Por otra parte, Hittinger se plantea en qué medida la ley natural puede afectar a la constitución politica y a la praxis judicial. Igual que Fuller, Hittinger sostiene que el Estado de derecho es una exigencia de la ley natural, y estudia de qué manera las diversas autoridades, políticas y judiciales, participan en un orden que se encuentra bajo el imperio de la ley natural.

Hittinger pone de manifiesto los riesgos y las contradicciones de intentar proteger los derechos naturales mediante la Constitución política, sin comprender bien lo qué significan. Igualmente, pone en entredicho la idea liberal de unos derechos naturales como libertades frente al poder politico.

Steven Long (nac. 1954), filósofo y teólogo, profesor de la Ave Maria University, discipulo de Hittinger, es uno de los tomistas norteamericanos que actualmente, junto con Hittinger y Jensen, critican con más fuerza la doctrina iusnaturalista de Grisez-Finnis. ${ }^{69}$

67 Russell Hittinger, The First Grace: Rediscovering Natural Law in a Post-Christian Age, Wilmington (Delaware), Isi Books, 2003.

68 Russell Hitringer, A Critique of the New Natural Law Theory, Notre Dame (Indiana), University of Notre Dame Press, 1987.

20469 Cfr. Steven A. Long, "St. Thomas Aquinas through the Analytic Looking-Glass", en Thomist 65 (2001), pp. 259-300. Y, especialmente, "Natural law or autonomous practical reason: Problems for the new natural law theory" en St. Thomas Aquinas and the Natural Law Tradition: Contemporary Perspectives, Washington D.C, The Catholic University of America Press, 2004, pp. 65-193. 
Contra la NNLT, Long explica que la naturaleza del bien, su orden teleológico, es anterior a la reivindicación del derecho sobre dicho bien. Un derecho es solo una justa pretensión, y para saber si una pretensión es justa, es preciso conocer la relación de dicha pretensión con un orden normativo de fines, que es anterior a la elección humana, y conocer las circunstancias que hacen justa dicha reivindicación (lo cual requiere un juicio prudencial). Los derechos no son lo primero, sino que se derivan de la naturaleza del bien.

Por otra parte, Long considera que la idea de bienes humanos básicos inconmensurables presupone una noción meramente subjetiva del bien, que a la postre no se sostiene, porque rompe la unidad del dinamismo natural teleológico y estructurado de la creación, de la que forma parte el hombre. Los bienes humanos son bienes para el hombre en la medida en que anticipan su participación en el fin hacia el que tiende su naturaleza. Si los bienes son fines que, antes de la elección humana, no se encuentran entrelazados en un orden natural hacia el fin último, no son propiamente bienes. Un ejemplo paradigmático, al que Long recurre con frecuencia, es el juicio que hacen los neoclásicos sobre la pena de muerte, que atenta directa y deliberadamente contra la vida humana (bien humano básico). Cuando las circunstancias no permitan una solución más adecuada para castigar al criminal y proteger a la sociedad, explica Long, puede haber una justificación, porque la vida de cada individuo está ordenada a un fin superior, como es la paz social, que garantiza la justicia.

Long se pregunta: ¿por qué motivo no podemos actuar en contra de ningún bien humano básico? El motivo es una noción de bien más universal, a la cual se subordinan los demás bienes. Esta falta de ordenación de bienes, previa a la elección, nos conduce a soluciones absurdas. Si, como dicen los defensores de la NNLT, no estamos obligados a incluir en nuestro "plan de vida" todos los bienes humanos básicos, uno podría, por ejemplo, prescindir del bien humano de la religión, o de la "racionalidad práctica", y no pasaría nada. O llevado al extremo, ¿podría perseguir solo el bien humano básico del juego dejando de lado los demás bienes (sin despreciarlos)? Pero si tienen que perseguir los demás bienes, ¿en qué medida?, ¿bajo qué criterio? Para los neoclásicos es una cuestión confiada al arbitrio de cada cual, porque no hay una correcta disposición de bienes previa a la elección del hombre. Y esta es la clave.

Por otra parte, Long argumenta que la NNLT desarrolla una incorrecta teoría de la acción intencional para salvar su tesis de que nunca se puede actuar contra un bien humano básico. Y así, por ejemplo, quien intentó matar a Hitler, en realidad no quería atentar contra la vida, sino salvar a su pueblo. Con este argumento desaparece la noción clásica de finis operis, clave de la filosofia moral.

Por último, Long critica la concepción neoclásica de la razón práctica, al separarla radicalmente de la razón especulativa, en la configuración del razonamiento moral. La NNLT, explica Long, presenta la "racionalidad práctica" como un estatuto propio, que ni es propiamente razón, ni voluntad, sino un "conocer en términos de fin". Long defiende la tesis tomista de que todo conocimiento es, en su raíz, 
especulativo, y que solo en cuanto se ordena a un fin es también práctico. Por contraste, los defensores de la NNLT, a los que Long considera mucho más próximos a Kant o a Hume que a Santo Tomás, piensan que la naturaleza práctica del conocimiento de ninguna manera se deriva del especulativo. Con frecuencia consideran que cualquier derivación desde el conocimiento especulativo se hace a modo de una deducción lógica; pero - explica Long- el anclaje en el especulativo es más esencial que eso. Ciertamente, no podemos derivar una conclusión para la acción a partir de premisas que carecen de una razón para actuar. Pero es que antes del deseo de cualquier fin, necesitamos conocerlo, y este conocimiento es especulativo. El hecho de que entre las razones para obrar no se precise de una consideración de la naturaleza humana, no basta para probar que una adecuada consideración de la naturaleza contiene realmente motivos para el obrar. En términos epistemológicos y morales, el deseo de los bienes presupone necesariamente un anterior conocimiento especulativo. Por otra parte, el juicio prudencial se realiza sobre juicios especulativos. Negar esto, concluye Long, equivale a tratar la naturaleza del propio proyecto vital como determinante de la verdad de la naturaleza de las cosas.

El juicio de Long sobre la NNLT no puede ser más duro: inicialmente desarrollada para enfrentarse al proporcionalismo, termina por enfrentarse con la tradición clásica aristotélico-tomista, "ofreciéndonos una peor amalgama de los errores ilustrados mezclados con la lógica analítica”.

Steven Jensen (nac. 1965) es actualmente, en mi opinión, el autor iusnaturalista norteamericano más interesante. Su reciente libro Knowing the Natural Law $(2015)^{70}$ es una obra preclara sobre el modo en que conocemos la ley natural. Es un estudio sobre la naturaleza de la razón práctica, que deja en evidencia, por un lado, las limitaciones del proyecto moderno de separar el deber ser del ser, y por otro, el error de Grisez y Finnis de intentar solventarlo mediante su peculiar teoría de la racionalidad práctica, que percibe, con conocimiento inmediato, los bienes humanos básicos.

Jensen parte de la consideración de los niveles del conocimiento práctico. Sobre la base de la distinción tomista recogida en la Suma Teológica (I, q. 14, a. 16), distingue cuatro niveles: primer nivel, "Conocimiento puramente especulativo": es el conocimiento de las realidades que el hombre no puede hacer ni producir de ningún modo, como, por ejemplo, Dios, los astros, etc. Segundo nivel, "Conocimiento materialmente práctico": es el conocimiento de realidades (operables o factibles) que pueden ser realizadas por el hombre, por ejemplo, un motor, una canción, pero sin intención de realizarlas, ni de conocer el modo de realizarlas. Tercer nivel, "Conocimiento virtualmente práctico": es el conocimiento del modo de hacer o producir algo o de conseguir un objetivo. Cuarto nivel, "Conocimiento completamente práctico": es el conocimiento en orden a una acción que el agente ha decidido llevar a cabo. Jensen muestra que el conocimiento en cualquiera de estos 
cuatro niveles presupone siempre los anteriores. Así, por ejemplo, nadie puede saber cómo se fabrica un motor (tercer nivel) si previamente no sabe lo que es un motor (segundo nivel), y menos todavía puede lanzarse a fabricarlo (cuarto nivel) si no sabe cómo se hace (tercer nivel). Obviamente, el primer nivel se presupone, pues nos permite distinguir lo que es o puede ser fruto de la acción humana de lo que está completamente fuera de su dominio. El desconocimiento de esos cuatro niveles, explica Jensen, nos incapacita para comprender la estructura del razonar práctico, y, por tanto, del modo en que conocemos la ley natural. A lo largo de su libro Knowing Natural Law desarrolla estos cuatro niveles de conocimiento proyectándolos sobre el conocimiento de la ley natural, y mostrando cómo se entrecruzan el conocimiento especulativo y el práctico en todo el obrar humano.

Por otra parte, Jensen trata de demostrar que el conocimiento práctico no es independiente del especulativo, y lo hace al responder a los cuatro argumentos básicos esgrimidos por los defensores de la NNLT.

En primer lugar, el argumento de que no se pueden derivar proposiciones prácticas desde proposiciones especulativas, ante el cual Jensen denuncia la ambigüedad del término "derivación". Si lo entendemos en sentido estricto, como una deducción o inferencia lógica, ciertamente los neoclásicos tienen razón: ni el mismo santo Tomás pretendió deducir de un modo silogístico un deber ser a partir de un ser. Pero en un sentido amplio, santo Tomás sí hace derivar el deber ser desde el ser. Pero entonces, se pregunta Jensen, ¿por qué tanta insistencia de los neoclásicos en mantener la validez de la crítica de la falacia naturalista?

En segundo lugar, el argumento de la distinción entre el orden del conocimiento y el orden del ser. Finnis explica que los bienes humanos básicos son primeros en el orden del conocimiento, y reconoce que su existencia se funda en la naturaleza humana. El orden del conocimiento presupone el orden del ser. Finnis pone el siguiente ejemplo: ontológicamente, el planeta Neptuno provoca ciertas irregularidades en la órbita de Urano; epistemológicamente, sin embargo, Le Varrier pudo afirmar la existencia de Neptuno porque conoció primero la órbita irregular de Urano. De modo análogo, la naturaleza humana la conocemos como Le Varrier conoció Neptuno: a partir de sus efectos en Urano. De acuerdo, explica Jensen, pero también sucede a la inversa: al conocer la existencia de Urano podemos deducir otros efectos. Desde el conocimiento de los bienes evidentes conocemos la naturaleza humana, pero nada impide que podamos también realizar el recorrido inverso: una vez conocida, la naturaleza nos permite comprender mejor los principios del obrar.

El tercer argumento al que se enfrenta Jensen es el de la crítica de "fisicalismo" aplicada a todo aquel que pretenda derivar el deber ser desde el ser. Se considera "fisicalista" al que pretende fundamentar el deber moral únicamente en el dinamismo natural de las tendencias orgánicas. Los neoclásicos critican este argumento porque trata de fundamentar el deber moral en un dinamismo físico, independiente de la voluntad. Desde la perspectiva fisicalista, la razón es un simple mensajero entre la naturaleza del organismo y la voluntad, que informa si la acción 
elegida es contraria o no al dinamismo de la naturaleza. Para el fisicalismo, la ley natural es ley de una naturaleza orgánica, que la razón solo descubre impresa en las tendencias, una ley que la razón no constituye. Sin embargo, los neoclásicos insisten en que la ley natural es ley de la razón. La razón no solo descubre lo que se esconde en la naturaleza, sino que ella misma configura también su objeto (el bonum rationis del que habla Rhonheimer). ${ }^{71}$ Los neoclásicos, y también Rhonheimer, explican que la ley natural es un producto de la razón, no de un organismo prerracional ante el cual la razón humana, como observador, levanta el acta de la ley natural. Jensen comparte esta crítica, y entiende que la ley natural es un producto de la razón, pero no hasta el punto de dejar a un lado el estudio de las inclinaciones humanas prerracionales como elemento fundamental en el conocimiento de la ley natural.

El cuarto argumento en favor de la separación del conocimiento especulativo y práctico, al que se enfrenta Jensen, se resume en negar la posibilidad de que el conocimiento especulativo mueva a obrar. Ciertamente, solo el conocimiento puramente práctico del bien, en términos de fin de mi propia acción, mueve a obrar. Pero este conocimiento presupone los otros niveles de conocimiento, como hemos visto, lo cual Jensen explica claramente y constituye el nervio de su Knowing Natural Law.

En definitiva, la ley natural, según Jensen, es parte de la naturaleza, inseparable de lo que ya somos. Su fuerza imperativa no surge desde una especial fuerza motriz de la razón humana ("la racionalidad práctica”), sino que procede de lo que ya somos.

La división real entre Sto. Tomás y la ética moderna no es tanto si podemos o no derivar el deber ser del ser, sino si tenemos o no una naturaleza humana con una fuerza interior [impetus] que nos impulsa hacia la plenitud. Si se prescinde de esta naturaleza, la ética es un simple juego. ${ }^{72}$

Jensen explica que Dios dirige a sus criaturas por medio de sus inclinaciones, tanto orgánicas como espirituales (la voluntad es una inclinación nativa hacia el bien que le presenta la razón). Y en el caso del hombre, Dios lo dirige dándole el poder de comprender sus inclinaciones y de seguirlas libremente. Toda naturaleza es un impulso interior y permanente hacia la plenitud de su forma. En el hombre, las fuerzas apetitiva y cognoscitiva están diseñadas para interaccionar reciproca y continuamente en busca de un único fin, que es la plenitud personal. Dios ha creado la voluntad (apetito racional) como un poder que busca el bien de la persona entera (no bienes parciales que agotan la razón de fin), y es en vista de este fin como la razón, interactuando con la voluntad, elige los medios para lograrlo. 
Matthew Levering (nac. 1971), actualmente profesor de teologia en Mundelein Seminary (Chicago), en una línea similar a la de Hittinger, aborda el estudio de la ley natural desde una perspectiva teológica. En su Biblical Natural Law ${ }^{73}$ explica que el estudio de la ley natural solo tiene sentido en el marco de una visión de la Creación en su conjunto, y desarrolla una teología de la ley natural comparándola con el pensamiento de los autores más relevantes de la modernidad, desde Descartes hasta Nietzsche. Levering critica la perspectiva antropocéntrica y autorreferencial de ética moderna, por contraste con la perspectiva bíblica teocéntrica, que sitúa el centro de la moral en el amor a Dios y al prójimo.

No podemos dejar este breve recorrido de los autores más influyentes en el iusnaturalismo norteamericano sin referirnos, por un lado, al profesor suizo Martin Rhonheimer (nac. 1950), cuyas obras mayores, traducidas al inglés, son conocidas y comentadas por la mayor parte de los tomistas norteamericanos en los últimos veinte años. Especialmente su Natural Law and Practical Reason ${ }^{74}$ y The Perspective of Morality: Philosophical Foundations of Thomistic Virtue Ethics. ${ }^{75}$ Y, por otro lado, al profesor italiano Fulvio Di Blasi, que fue profesor en la Universidad de Notre Dame, cuya obra God and the Natural Law (ampliamente referenciada en Estados Unidos) muestra la inconsistencia de las doctrinas iusnaturalistas que teorizan sobre una ley natural $\sin$ Dios. ${ }^{76}$

\section{REVISTAS Y CONGRESOS}

En Estados Unidos, actualmente, entre las publicaciones periódicas que contienen numerosos e importantes artículos sobre la ley natural, las cinco más importantes son: The American Journal of Jurisprudence, The Thomist, Nova et Vetera (version inglesa), First Things y American Catholic Philosophical Quarterly, a las que nos referiremos a continuación.

En 1947, se crea el Natural Law Institute en Notre Dame Law School, por influencia de Jacques Maritain. En 1956, surge en el seno de dicho instituto la primera y más influyente publicación iusnaturalista en Estados Unidos: The Natural Law Forum, que se editó hasta $1968 .{ }^{77}$ Desde 1970 continúa publicándose bajo el nombre The American Journal of Jurisprudence. ${ }^{78}$

73 Mathew Levering, M., Biblical Natural Law: A Theocentric and Teleological Approach, Oxford, Oxford University Press, 2008.

74 Martin Rhonheimer, Natural Law and Practical Reason: A Thomist View of Moral Autonomy, op. cit.

75 Martin Rhonherimer, The Perspective of Morality: Philosophical Foundations of Thomistic Virtue Ethics, Washington D.C., Catholic University of America Press, 2011.

76 Fulvio Di Blasi, God and the Natural Law: A Rereading of Thomas Aquinas, South Bend (IN), St. Augustine's Press, 2002.

77 Todos los artículos publicados en el Natural Law Forum están disponibles en: http://scholarship.

78 Véase http://scholarship.law.nd.edu/ajj/. 
En 1939, ve la luz el primer número de la revista The Thomist. ${ }^{79}$ Se trata de una publicación de periodicidad trimestral editada por los dominicos incardinados en la Provincia de San José, que comprende los Estados del norte de la costa este de Estados Unidos. ${ }^{80}$ La revista contiene estudios relacionados con el pensamiento de santo Tomás, por lo que también hay numerosos estudios sobre la ley natural. En su web se ofrecen los artículos completos y recensiones publicados en los últimos cuarenta años. ${ }^{81}$

En 2003, aparece la edición inglesa de la tradicional revista Nova et Vetera, cuya edición original (francesa) fue fundada en 1926, por iniciativa del que sería luego el cardenal Charles Journet, en colaboración con Jacques Maritain. La edición inglesa, fundada por Matthew Levering, no es una traducción de la francesa, sino una revista independiente, pero comparte con la original su espiritu y finalidad. Su objeto son todas las cuestiones teológicas y filosóficas relacionadas con la tradición del pensamiento cristiano desde la perspectiva tomista. En ella encontramos numerosos artículos y recensiones sobre cuestiones relacionadas con la ley natural. No en vano su fundador, Matthew Levering, como hemos visto, es el autor del libro Biblical Natural Law y de numerosos estudios relacionados con la ley natural. La edición inglesa se publica trimestralmente por el Augustine Institute. Nova et Vetera, junto con el Augustine Institute, también organiza anualmente congresos en Denver (Colorado) y publica la serie de libros "Nova et Vetera".

First Things ${ }^{82}$ es una revista mensual, publicada por el Institute on Religion and Public Life, una organización interreligiosa que fomenta y divulga la investigación y educación independiente. Dicho Instituto fue fundado en 1990 por Richard John Neuhaus, como contrapeso a la ideología secularista difusora del tópico de que el ámbito de lo público ha de ser "neutral" y que la fe no tiene que influir para nada en el debate púbico ni en la política. En la revista se publican regularmente artículos relacionados con la ley natural. Entre sus numerosos colaboradores se encuentran las figuras más destacadas del iusnaturalismo norteamericano, muchas de las cuales hemos tratado ya en estas páginas.

The American Catholic Philosophical Quarterly es la revista de la American Catholic Philosophical Association (ACPA) (institución a la que luego nos referimos). Inicialmente se llamó The New Scholasticism, ${ }^{83}$ revista fundada en 1927 como la publicación oficial de la ACPA. A partir de 1990 adoptó el nombre de American Catholic Philosophical Quarterly. Íntimamente relacionada con ella son las actas de los congresos anuales de la ACPA, Proceedings of the American Catholic Philosophical Association. En ella encontramos trabajos de autores como Mortimer Adler,

79 Véase la declaración de intenciones de la revista en su primer número publicado en 1939, en http://www.thomist.org/index.html.

80 Kentucky, las dos Virginias, Washington D.C., Maryland, Delawere, New Jersey, Connecticut, Rhode Island, New York, Massachusetts, Vermont, New Hamphsire, Maine y Ohio.

81 Véase www.thomist.org.

82 Véase www.firstthings.com.

83 Cfr. https://www.pdcnet.org/newscholas. 
Frederick Copleston, Étienne Gilson, Germain Grisez, Walter Lippmann, Bernard Lonergan, Jacques Maritain, Paul Ricoeur...

Por lo que respecta a los congresos periódicos donde se abordan cuestiones relacionadas con la ley natural desde la perspectiva tomista, destacamos tres: los encuentros anuales organizados por The American Catholic Philosophical Association, The International Congress on Medieval Studies y The Fellowship of Catholic Scholars.

The American Catholic Philosophical Association (ACPA), ${ }^{84}$ fundada en 1926, reúne a intelectuales, principalmente de Canadá y Estados Unidos, para profundizar desde una perspectiva cristiana (católica) en cuestiones de actualidad. La ACPA organiza encuentros que tienen lugar cada año en una ciudad diferente (siempre dentro de Estados Unidos). En concreto, el congreso anual previsto para 2016 se celebró en San Francisco con el título "Justice: Then and Now".

El International Congress on Medieval Studies es el congreso medievalista más importante de Estados Unidos, un evento que se celebra en la Western Michigan University (en Kalamazoo) y reúne cada año a más de 3.000 académicos. En este contexto, desde hace años tienen lugar los encuentros de los mejores tomistas norteamericanos, en diversos workshops, especialmente los organizados por el Center for Thomistic Studies de la University of St. Thomas (ubicada en Houston, Texas). ${ }^{85}$ Obviamente, son una pequeña parte dentro del congreso, en el que se organizan encuentros de los temas más variopintos relacionados con la Edad Media. Pero lo cierto es que la ocasión es aprovechada por los diversos centros tomistas del país para reunirse. He tenido la ocasión de participar durante cuatro años en estos encuentros, y de ahí surgió mi creciente interés por el tema que desarrollo en este trabajo.

The Fellowship of Catholic Scholars ${ }^{86}$ es una asociación de intelectuales católicos en Estados Unidos, fundada en 1977 con el fin de crear una red de colaboración intelectual entre todos aquellos que puedan contribuir al conocimiento de las verdades más importantes sobre el origen, la vida y el destino del hombre, fundados en la convicción de la verdad revelada por Cristo y confiada a su Iglesia. Esta asociación también organiza encuentros anuales en diversas ciudades del país. En concreto, en 2016 se llevó a cabo el congreso en Washington D.C., bajo el título "Science and Religion".

\section{SELECCIÓN BIBLIOGRÁFICA}

En este capítulo incluimos una lista de libros y artículos especialmente importantes para comprender el iusnaturalismo en Estados Unidos a lo largo del siglo XX.

\footnotetext{
84 Véase http://www.acpaweb.org.

85 Véase http://www.stthom.edu/Academics/Centers_of_Excellence/Center_for_Thomistic_Studies/ About_the_Center/Index.aqf.

86 Véase http://www.catholicscholars.org/.
} 
Como vimos en la introducción, no todos son norteamericanos, pero todos tienen especial relevancia en el iusnaturalismo de Estados Unidos.

ADLER, Mortimer, Aristotle for Everybody, New York, Tochstone, 1978.

AdLer, Mortimer, "A Sound Moral Philosophy", en Reforming Education: The Opening of the American Mind, New York, Collier Books \& Macmillan Publishing, 1990, pp. 254-62.

Anscombe, G. E. M., "Modern moral philosophy", en Ethics, Religion, and Politics, 26-42. Minneapolis: University of Minnesota Press, 1981, originalmente en Philosophy, 33/124 (Jan. 1958), pp. 1-19.

Ayers, Michael R., "Locke versus Aristotle on natural kinds", en Journal of Philosophy, 78/5 (May 1981), pp. 247-72.

BigGaR, Nigel (y Black, Rufus), The revival of Natural Law, London-New York, Routledge, 2000.

BoyLe, Joseph M., "Practical reasoning and moral judgment", en Proceedings of the American Catholic Philosophical Association 58 (1984), pp. 37-49.

BRock, Stephen L., "The legal character of natural law according to St Thomas Aquinas", Tesis doctoral (Ph.D. dissertation), University of Toronto, 1988.

BRock, Stephen L., "Natural inclination and the intelligibility of the good in thomistic natural law", en Vera Lex 6 (2005), pp. 57-78.

BRock, Stephen L., "Natural Law, the Understanding of Principles, and Universal Good”, Nova et Vetera (English edition) 9 (2011), pp. 671-706.

ButERA, Giuseppe, "The moral status of the first principle of practical reason in Thomas's natural-law theory", Thomist 71 (2007), pp. 609-31.

CHAPPELl, Timothy, "Natural law revived: Natural law theory and contemporary moral philosophy", en The Revival of Natural Law: Philosophical, Theological and Ethical Responses to the Finnis-Grisez School, ed. por Nigel Biggar y Rufus Black, Sydney, Ashgate, 2000, pp. 29-52.

Davidson, Donald, "How is weakness of will possible", en Essays on Actions and Events, 21-42. Oxford, Clarendon Press, 1980.

DAvies, Brian, The Thought of Thomas Aquinas, Oxford, Oxford University Press, 1992.

Dewan, Lawrence, "Jacques Maritain and the Philosophy of Cooperation", en L'Altérité, vivre ensemble différents: approches pluridisciplinaires, coord. por Michel Gourges and Gilles-D Mailhiot, Montreal, Editions Bellarmin, 1986, pp. 109-17.

Dewan, Lawrence, "St. Thomas, our natural lights, and the moral order", Angelicum 67 (1990), pp. 285-307.

Dewan, Lawrence, "St. Thomas, John Finnis, and the political good", Thomist 64 (2000), pp. 337-74. 
DEwAn, Lawrence, "Natural law in the first act of freedom: Maritain revisited", en Wisdom, Law, and Virtue, New York, Fordham University Press, 2008, pp. 231-41.

Di Blasi, Fulvio, God and the Natural Law: A Rereading of Thomas Aquinas, St. Bend (Ind.), Augustine's Press South, 2006.

Donagan, Alan, "The scholastic theory of moral law in the modern world", Proceedings of the American Catholic Philosophical Association (1966), pp. 29-40.

Donagan, Alan, Human Ends and human Actions: An Exploration in St. Thomas's Treatment, Milwaukee, Marquette University Press, 1985.

Dworkin, Ronald, "Interview", in Bryan Magee, Men of Ideas, New York, Viking Adult, 1978, pp. 242-60.

Dworkin, Ronald, "Natural' law revisited”, en University of Florida Law Review 34/2 (Winter, 1982), pp. 165-88.

Dworkin, Ronald, A matter of Principle, especialmente el ensayo "Libaralism”, de la parte tercera del libro, Cambridge, Mass., Harvard, 1985, pp. 181-204.

FinNis, John y GRISEz, Germain, "The basic principles of natural law: A reply to Ralph Mclnerny", en American Journal of Jurisprudence 26 (1981), pp. 21-31

FinNis, John, Natural Law and Natural Rights, Oxford, Clarendon Press, 1980.

FinNis, John, "Natural law and the 'ls'-'Ought' Question: An invitation to professor veatch", en Catholic Lawyer 26 (1981), pp. 266-77.

FINNIS, John, "Natural inclinations and natural rights: Deriving 'Ought' from 'Is' according to Aquinas", en Lex et Libertas: Freedom and Law according to St. Thomas Aquinas, vol. 30, ed. por Leo Elders y Klaus Hedwig, Roma, Studi Tomistici, 1987, pp. 43-55.

FInNIS, John, Aquinas: Moral, Political and Legal Theory, Oxford, Oxford University Press, 1998.

FinNIS, John, Fundamentals of Ethics, Georgetown, Georgetown University Press, 1983.

FlanNery, Kevin L., "The aristotelian first principle of practical reason", en Thomist 59 (1995), pp. 441-64.

Flannery, Kevin L., Acts Amid Precepts: The Aristotelian Logical Structure of Thomas Aquinas's Moral Theory, Washington, D.C., The Catholic University of America Press, 2001.

Fuippen, Douglas, "Natural law and natural inclinations", New Scholasticism 60 (1986), pp. 284-316.

Foot, Philippa, Natural Goodness, Oxford, Clarendon Press, 2001.

Fоoт, Philippa, "Goodness and choice", en The Is-Ought Question: A Collection of Papers on the Central Problem in Moral Philosophy, coord. por W. D. Hudson, London, Macmillan, 1969, pp. 214-27. 
Foot, Philippa, "Morality as a system of hypothetical imperatives", en Virtues and Vices and Other Essays in Moral Philosophy, Berkeley \& Los Angeles, University of California Press, 1978, pp. 157-73.

Foot, Philippa, "Moral beliefs", en The Is-Ought Question: A Collection of Papers on the Central Problem in Moral Philosophy, coord. por W. D. Hudson, London, Macmillan, pp. 196-213.

Fuller, Lon, "Positivism and fidelity to law", en Harvard Law Review 71 (1958), pp. 630-72.

Fuller, Lon, The Morality of Law, New Haven (Connecticut), Yale University Press, 1964.

GEACH, Peter T., “Good and Evil”, Analysis 17 (1956), pp. 33-42.

GEACH, Peter, Mental Acts: their content and their objects, New York, The Humanities Press, 1953.

George, Robert P., "Natural law and human nature", en Natural Law Theory: Contemporary Essays, coord. Por Robert P. George, Oxford, Clarendon Press, 1992, pp. 31-41.

Gilson, Etienne, The Unity of Philosophical Experience, New York, Ignatius Press, 1937. GiLson, Etienne, The Christian Philosophy of Thomas Aquinas, New York, Random House, 1956.

Goduing, Martin, "Aquinas and some contemporary natural law theories", Proceedings of the American Catholic Philosophical Association 48 (1974), pp. 238-47.

Gomez-Loвo, Alfonso, Morality and the Human Goods. An Introduction to Natural Law Ethics, Washington, Georgetown University Press, 2001.

Gomez-Loвo, Alfonso, "Natural law and naturalism", Proceedings of the American Catholic Philosophical Association 59 (1985), pp. 232-49.

GotThelf, Alan, “Aristotle's conception of final causality”, Review of Metaphysics 30 (2) (1976), pp. 226-54.

Grisez, Germain, Finnis, John y BoYLe, Joseph M., "Practical principles, moral truth, and ultimate ends", en American Journal of Jurisprudence 32 (1987), pp. 99-151.

GrISEz, Germain, Contraception and the Natural Law, Milwaukee, Bruce Publishing Company, 1964.

GRISEZ, Germain, "The first principle of practical reason: A commentary on the Summa Theologiae, 1-2, Question 94, Article 2", Natural Law Forum 10 (1965), pp. 168-201.

GRIsEz, Germain, "The structures of practical reason", Thomist 52 (1988), pp. 269-91.

GrISEz, Germain, "Natural law, God, religion, and human fulfillment", en American Journal of Jurisprudence 46 (2001), pp. 3-36. 
Grisez, Germain, "The true ultimate end of human beings: The kingdom, not god alone", en Theological Studies 69 (2008), pp. 38-61.

Harre, Rom y Madden, Eduard H., Causal Powers, NJ, Totowa, 1975.

HARRIS, Errol, "Natural law and naturalism", International Philosophical Quarterly 23 (1983), pp. 115-24.

HART, Herbert L. A., "Positivism and the separation of law and morals", en Harvard Law Review 71 (1958), pp. 593-629.

Hart, Herbert L. A., The Concept of Law, Oxford, Oxford University Press, 1961.

Hayden, R. Mary, "Natural inclinations and moral absolutes: A mediated correspondence for aquinas", en Proceedings of the American Catholic Philosophical Association 64 (1990), pp. 130-50.

Hittinger, Russell, A Critique of the New Natural Law Theory, Notre Dame, Ind., 1987.

Hittinger, Russell, "After Maclntyre: Natural law theory, Virtue Ethics and Eudaimonia”, en International Philosophical Quarterly 29 (4) (1989), pp. 449-61.

HitTinger, Russell, "Natural law and virtue: Theories at cross purposes", Natural Law Theory: Contemporary Essays, ed. Robert P. George, ed., Oxford, 1992, pp. 42-70.

Hittinger, Russell, The First Grace: Rediscovering Natural Law in a Post-Christian Age, Wilmington (Delaware), Isi Books, 2003.

JACOBS, James M., "The precepts of the decalogue and the problem of self- evidence”, en International Philosophical Quarterly 47 (2007), pp. 399-415.

Jensen, Steven J., "The error of the passions", Thomist 73 (2009), pp. 349-79.

Jensen, Steven J., Good and Evil Actions: A Journey through St. Thomas Aquinas, Washington D.C., The Catholic University of America Press, 2010.

Jensen, Steven J., Knowing Natural Law, Washington, The Catholic University Press, 2015.

KNIGHT, Frank, "Natural law: Last refuge of the bigot", en Ethics 59 (2) (1949), pp. 127-135.

LEE, Patrick, "Is Thomas's natural law theory naturalist?", American Catholic Philosophical Quarterly 71 (1997), pp. 567-87.

LeVErIng, Matthew, Biblical Natural Law: A Theocentric and Teleological Approach, Oxford, Oxford University Press, 2008.

Lisska, Anthony J., "Finns and Veatch on natural law in Aristotle and Aquinas", en American Journal of Jurisprudence, 36 (1991), pp. 55-71.

Lisska, Anthony J., Aquinas's Theory of Natural Law: An Analytic Reconstruction, Oxford, Clarendon Press, 1996. 
Lombardo, Nicholas E., The Logic of Desire: Aquinas on Emotion, Washington D.C., The Catholic University of America Press, 2011.

Long, Steven A., "St. Thomas Aquinas through the analytic looking-glass", Thomist 65 (2001), pp. 259-300.

LoNG, Steven A., "Natural law or autonomous practical reason: Problems for the new natural law theory", en St. Thomas Aquinas and the Natural Law Tradition: Contemporary Perspectives, coord. por John Goyette, Mark Latkovic y Richard S Myers, Washington D.C., The Catholic University of America Press, 2004, pp. 65-193.

Long, Steven A., The Teleological Grammar of the Moral Act, Naples (Florida), Sapientia Press, 2007.

MacInTYre, Alasdair, After Virtue: A Study in Moral Theory, Notre Dame (Indiana), University of Notre Dame Press, 1984.

MacInTYRE, Alasdair, A Short History of Ethics (1966), reedit. y ampliado, Notre Dame (Indiana), University of Notre Dame Press, 1998.

MacInTYRE, Alasdair, Whose Justice? Which Rationality?, Notre Dame University Press, Notre Dame (Indiana), 1988.

MacIntyre, Alasdair, Three Rival Versions of Moral Enquiry, Notre Dame (Indiana), Notre Dame University Press, 1990.

Maritain, Jacques, Man and the State (1951), Washington D.C., Catholic University of America Press, 2012.

Maritain, Jacques, Scholasticism and Politics (1940), University Park (Illinois), Liberty Fund Inc., 2011.

MARTin, Christopher, "The fact/value distinction", en Human Values: New Essays on Ethics and Natural Law, ed. David Oderberg and Timothy Chapell, New York, Palgrave Macmillan, 2004, pp. 52-69.

Martin, Patrick H., "Natural law: Voegelin and the end of [legal] philosophy", Louisiana Law Review 62 (3) (2002).

Martínez Martínez, Julio Luis S.J., Consenso público y moral social: las relaciones entre catolicismo y liberalismo en la obra de John Courtney Murray, Madrid, Universidad Pontificia de Comillas, 2002.

Matava, Robert J., “'Is', 'Ought' and Moral Realism: The roles of nature and experience in practical understanding”, en Studies in Christian Ethics 24 (2011), pp. 311-28.

Matava, Robert J., "On knowing the natural law: A response to Steven Jensen", en The American Journal of Jurisprudence 61 (2) (2016), pp. 237-257.

McInerny, Ralph, "Naturalism and thomistic ethics”, Thomist 40 (1976), pp. 222-42. 
McInerny, Ralph, "The principles of natural law", en American Journal of Jurisprudence, 25 (1980), pp 1-15.

McInerny, Ralph, Aquinas on Human Action: A Theory of Practice, Washington D.C., The Catholic University of America Press, 1992.

McInerny, Ralph, Ethica Thomistica: The Moral Philosophy of Thomas Aquinas, Washington D.C., The Catholic University of America Press, 1997

McInerny, Ralph, "Grisez and Thomism”, en The Revival of Natural Law: Philosophical, Theological and Ethical Responses to the Finnis-Grisez School, coord. por Nigel Biggar y Rufus Black, Ashgate, Sydney, 2000, pp. 53-72.

McInerny, Ralph, A First Glance of St. Thomas Aquinas, Notre Dame (Indiana), University of Notre Dame Press, 1990.

Michel, Florian, La Pensée Catholique en Amérique du Nord (Réseaux Intellectuels et Échanges Culturels entre l'Europe, le Canada et les Etats-Unis), Paris, Desclée de Brouwer, 2010.

Moore, George E., Principia Ethica (1903), New York, Barnes and Noble Books, 2005.

Morrisset, Paul, "Prudence et fin selon St. Thomas", Sciences Ecclesiastiques 15 (1963), pp. 73-98, 439-458.

MuRPHy, Mark C., "Self-evidence, human nature, and natural law", American Catholic Philosophical Quarterly 69 (1995), pp. 471-84.

Murphy, Mark C., Natural Law and Practical Rationality, Cambridge, Cambridge University Press, 2001.

MurRaY, John Courtney, We Hold These Truths (1960), Lanham (Maryland), Sheed \& Ward, 2005.

Nelson, Daniel Mark, The Priority of Prudence: Virtue and Natural Law in Thomas Aquinas and the Implications for Modern Ethics, University Park (Pennsylvania), Pennsylvania State University Press, 1992.

Nielsen, Kai, "An examination of the thomistic theory of natural law", en Natural Law Forum 4 (1959), pp. 63-71.

NiELSEn, Kai, "The myth of natural law", en Law and Philosophy: A Symposium, coord. por Sydney Hook, New York, New York University Press, 1964, pp. 122-43.

Nussbaum, Martha, Aristotle’s De Motu Animalium, Princeton, NJ, 1978.

Nussbaum, Martha, The Fragility of Goodness, Cambridge, Cambridge University Press, 1986.

Nussbaum, Martha, "Non-relative virtues", en The Guality of Life, Oxford, Oxford University Press, 1993, pp. 242-69.

Nussbaum, Martha, Love’s Knowledge, New York, Oxford University Press, 1990. 
O’Connor, D. J., Aquinas and Natural Law, London, Macmillan, 1967.

Passerin D'entreves, Alessandro, Natural Law, Hutchinson University Library, 1951 (trad. it. La dottrina del diritto naturale, Torino, 1954).

Paterson, Craig, "Finnis, non-naturalism, and Aquinas", en Analytical Thomism: Traditions in Dialogue, coord. por Craig Paterson \& Matthew S. Pugh, Aldershot (U.K.), Ashgate, 2006, pp. 171-94.

Poole, Diego, "Grisez y los primeros principios de la ley natural", en Persona y Derecho 52 (2005), pp. 339-393.

PRIOR, Arthur N., "The ethical copula”, en Australasian Journal of Philosophy 29 (1951), pp. 137-54.

Rautenberg, Joseph, "Does the Grisez-Finnis-Boyle moral —and Philosophy Rest on a Mistake?”, en Review of Metaphysics 44 (June 1991), pp. 807-30.

Rhonheimer, Martin, Natural Law and Practical Reason: A Thomist View of Moral Autonomy, New York, Fordham University Press, 2000.

RHONHEIMER, Martin, "The cognitive structure of the natural law and the truth of subjectivity", en The Perspective of the Acting Person: Essays in the Renewal of Thomistic Moral Philosophy, Washington D.C., The Catholic University of America Press, 2008, pp. 158-94.

Rhonheimer, Martin, "The moral significance of pre-rational nature in Aquinas: A reply to Jean Porter (and Stanley Hauerwas)", en The Perspective of the Acting Person: Essays in the Renewal of Thomistic Moral Philosophy, Washington D.C., The Catholic University of America Press, 2008, pp. 129-57.

RHonheimer, Martin, "Practical reason and the 'naturally rational': On the doctrine of the natural law as a principle of praxis in Thomas Aquinas", en The Perspective of the Acting Person: Essays in the Renewal of Thomistic Moral Philosophy, Washington D.C., The Catholic University of America Press, 2008, pp. 95-128.

RHonheimer, Martin, "Natural law as a 'work of reason': Understanding the metaphysics of participated theonomy", en American Journal of Jurisprudence 55 (2010), pp. 41-77.

Rhonheimer, Martin, The Perspective of Morality, Philosophical Foundations of Thomistic Virtue Ethics, Washington D.C., The Catholic University of America Press, 2011.

Rommen, Heinrich A., The Natural Law: A Study in Legal and Social History and Philosophy (1936 vers. original alemana), Indianapolis, Liberty Fund, 1998.

RyAn, Columba, "The traditional concept of natural law: An interpretation", en Light on the Natural Law, coord. por Illtud Evans, Baltimore, Helicon Press, 1965, pp. 13-37.

Schultz, Janice L., "'Ought'-judgments: A descriptivist analysis from a thomistic perspective”, en New Scholasticism 61 (1987), pp. 400-26. 
Schultz-AldRich, Janice L., "Revisiting Aquinas on 'naturalism': A response to Patrick Lee”, en American Catholic Philosophical Quarterly 77 (2003), pp. 114-31.

Sigmund, Paul E., "Thomistic natural law and social theory", Anthony Pare (ed.), Calgary Aquinas Studies, Toronto, 1978, pp. 67-76.

Sigmund, Paul E., St. Thomas Aquinas on Politics and Ethics, New York, W. W. Norton \& Company, 1987.

Simon, Yves, The Tradition of Natural Law: A Philosopher's Reflections (1965), New York, Fordham University Press, 1999.

Slade, Francis, "Ends and purposes", en Final Causality in Nature and Human Affairs, coord. por Richard F. Hassing, Washington D.C., The Catholic University of America Press, 1997.

SMITH, Randall, "What the old law reveals about the natural law according to Thomas Aquinas", en Thomist 75 (2011), pp. 95-139.

Sokolowski, Robert, "What Is Natural Law? Human Purposes and Natural Ends", en Thomist 68 (2004), pp. 507-29.

Sokolowski, Robert, "Discovery and obligation in natural law", en Natural Moral Law in Contemporary Society, coord. por Holger Zaborowski, Washington D.C., The Catholic University of America Press, 2010.

STALEY, Kevin, "Metaphysics and the good life: Some reflections on the further point of morality”, en American Catholic Philosophical Quarterly 65 (1991), pp. 1-28.

Stevens, Gregory. "The relations of law and obligation", en Proceedings of the American Catholic Philosophical Association 29 (1955), pp. 195-205.

Sullivan, Robert P. "Natural necessitation of the human will", en Thomist 14 (1951), pp. 351-99, 490-528.

Tollefsen, Christopher, "The new natural law theory", en Lyceum 10 (2009), pp. 1-17.

Toulmin, Stephen, An Examination of the Place of Reason in Ethics, Cambridge, Cambridge University Press, 1970.

Tumulty, Peter, "A contemporary bridge from facts to values: But will natural law theorists pay the toll?", en International Philosophical Quarterly 28 (1988), pp. 53-63.

Veatch, Henry y Rautenberg, Joseph, "Does the Grisez-Finnis-Boyle moral philosophy rest on a mistake?”, en Review of Metaphysics 44 (1991), pp. 807-30.

Veatch, Henry B., Rational Man: A Modern Interpretation of Aristotelian Ethics, Bloomington (Indiana), Liberty Fund, 1962.

Veatch, Henry B., For an Ontology of Morals, Evanston (Illinois), Northwestern University Press, 1971. 
VEATCH, Henry B., "Review of natural law and natural rights", en American Journal of Jurisprudence 26 (1981), pp. 247-59.

Veatch, Henry B., Human Rights: Fact or Fancy?, Baton Rouge (Louisiana), Louisiana State University Press, 1985.

Veatch, Henry B., Swimming Against the Current in Contemporary Philosophy, Washington D.C., Catholic University of America Press, 1990.

Voegelin, Eric, "Nature of the law and related legal writings", en The collected works of Eric Voegelin, vol. 27, Columbia (MO), University of Missouri Press, 1991.

Weinreb, Lloyd, Natural Law and Justice, Cambridge (Mass.), Harvard University Press, 1987.

Westberg, Daniel, Right Practical Reason: Aristotle, Action and Prudence in Aquinas, Oxford, Clarendon Press, 1994.

White, Morton, The Philosophy of the American Revolution, New York, Oxford University Press, 1978.

Zimmerman, Michael, “The 'is-ought': An unnecessary dualism”, en The ls-Ought Question: A Collection of Papers on the Central Problem in Moral Philosophy, coord. por W. D. Hudson, London, Macmillan, 1969, pp. 83-91.

\section{CONCLUSIONES}

Actualmente, Estados Unidos es el país donde la reflexión iusnaturalista tiene mayor fuerza y profundidad. En este trabajo hemos mostrado el "estado del arte" del iusnaturalismo en Estados Unidos desde comienzo del siglo XX hasta nuestros dias. Se trata de una visión de conjunto, agrupada por afinidades ideológicas y con un cierto orden cronológico. Para comprender la historia del iusnaturalismo no bastan las categorias básicas de "iusnaturalismo clásico" o realista y "iusnaturalismo moderno" o racionalista. Hay otro binomio tanto o más importante: Natural Law Tradition y Natural Rights Tradition. El iusnaturalismo americano dominante se ha enmarcado sobre todo en la segunda categoria (Natural Rights Tradition). En cambio, el tomismo en Estados Unidos (enmarcado en el Natural Law Tradition) hasta la segunda mitad del siglo XX estaba relegado a las bibliotecas de los seminarios y de las órdenes religiosas. Es a partir de la década de los treinta cuando aparecen focos importantes de estudios tomistas, con el correspondiente iusnaturalismo, especialmente en las universidades de Chicago y de Notre Dame. Sin embargo, estos iusnaturalistas de los años treinta, venidos de Europa (Gilson, Maritain, Simon...), son como agentes extraños en el contexto mayoritariamente utilitarista y analítico de Estados Unidos. Tras la Segunda Guerra Mundial surgen en el contexto de la filosofia analítica una serie de autores que cambiarán el foco de la filosofia moral dominante: desde las normas hacia las virtudes. Aun sin ser propiamente tomistas, abonarán el terreno para un renacimiento tomista que se verifica en el tránsito del siglo XX al XXI, y que poco a poco va ganan- 
do protagonismo en el contexto de la filosofia ética, política y jurídica de Estados Unidos. A partir de los años setenta surge, por influjo de Germain Grisez, una nueva corriente iusnaturalista (New Natural Law Theory), cuyo máximo exponente es todavía John Finnis, con un planteamiento supuestamente tomista, pero que en realidad se aproxima categorias morales propias del kantismo. Frente a esta corriente, desde finales de los años ochenta hasta nuestros dias han surgido una serie de autores (Hittinger, Long, Jensen...) especialmente en el ámbito te la teología moral (Grisez también es teólogo moral), que reivindican una interpretación más fiel al pensamiento de santo Tomás.

\section{BIBLIOGRAFÍA ${ }^{87}$}

Aavv, Natural Law and Modern Society, New York, The World Publishing Company, 1963.

ADLER, Mortimer, Aristotle for everybody, New York, Tochstone, 1978.

AdLer, Mortimer, Reforming Education: The Opening of the American Mind, New York, Collier Books and Macmillan, 1990.

Anscombe, Elizabeth, “Modern moral philosophy”, en Philosophy 33 (124) (1958).

BARrett, William, Irrational Man: A Study in Existential Philosophy, New York, Anchor Books, 1956.

BRock, Stephen, "Natural inclinations and the intelligibility of the good in thomistic natural law", en Vera Lex VI (1-2) (2005), pp. 57-78.

CARPINTERo, Francisco, La ley natural, una realidad por explicar, México D.F., Universidad Autónoma de México, 2013.

Corwin, Edward S., "The ‘higher law' background of American Constitutional Law”, en Harvard Law Review 42 (3) (1929), pp. 365-409.

Di Blasi, Fulvio, God and the Natural Law: A Rereading of Thomas Aquinas, South Bend (IN), St. Augustine's Press, 2002.

Dworkin, Ronald, "Natural law revisited”, en University of Florida Law Review 34 (1982).

Finnis, John, Aquinas: Moral, Political, and Legal Theory, Oxford, Oxford University Press, 1998.

Finnis, John, Fundamentals of Ethics, Washington D.C., Georgetown University Press, 1983.

FinNis, John, Natural Law and Natural Rights, Oxford, Oxford University Press (Clarendon Law Series), 1980.

87 Aquí solo incluyo las obras citadas a pie de página a lo largo de este trabajo. En el apartado "Selección bibliográfica” ofrezco un elenco de las obras más significativas del iusnaturalismo en Estados Unidos, desde comienzos del siglo XX hasta nuestros días. 
GRISEz, Germain, "The first principle of practical reason", en American Journal of Jurisprudence 10 (1) (1965), pp. 168-201, traducido por Diego Poole en Persona y Derecho, 2005, en http://www.twotlj.org/EthicalTheory.html.

GrISEz, Germain, Beyond the New Morality: The Responsibilities of Freedom, Notre Dame, Notre Dame University Press, 1974.

Haine, Charles, The Revival of Natural Law Concepts (1930), Reedit. por William S Hein \& Co, Getzville (NY), 1979.

HitTinger, Russell, A Critique of the New Natural Law Theory, Notre Dame (Indiana), University of Notre Dame Press, 1987.

Hittinger, Russell, "Introducción a Rommen, H.”, The Natural Law: A Study in Legal and Social History and Philosophy (1936 vers. original alemana), Indianapolis, Liberty Fund, 1998.

Hittinger, Russell, The First Grace: Rediscovering Natural Law in a Post-Christian Age, Wilmington (Delaware), Isi Books, 2003.

Jensen, Steven, Knowing The Natural Law, Washington, The Catholic University Press, 2015.

KNight, Frank H., "Natural law: Last refuge of the bigot”, en Ethics 59 (2) (1949), pp. 127-135

Levering, Mathew, Biblical Natural Law: A Theocentric and Teleological Approach, Oxford, Oxford University Press, 2008.

Lisska, Anthony, Aquinas's Theory of Natural Law: An Analytic Reconstruction, Oxford, Clarendon Press, 1998.

Locke, John, "An Essay concerning the true original, extent and end of civil Government (1690)", en Two Treatises on Government, London, R. Butler \& others, 1821 (version disponible en www.bartleby.com/169/).

Long, Steven A. "St. Thomas Aquinas through the analytic looking-glass", en Thomist 65 (2001), pp. 259-300.

LoNG, Steven A., "Natural law or autonomous practical reason: problems for the new natural law theory" en St. Thomas Aquinas and the Natural Law Tradition: Contemporary Perspectives, Washington D.C, The Catholic University of America Press, 2004, pp. 65-193.

MacIntyre, Alasdair, After Virtue, Notre Dame, Notre Dame Univerity Press, 1981.

Martin, Patrick H., "Natural Law: Voegelin and The End of [Legal] Philosophy", en Louisiana Law Review 62 (3) (2002).

Martínez, Julio Luis, S.J., Consenso público y moral social: las relaciones entre catolicismo y liberalismo en la obra de John Courtney Murray, Madrid, Univiversidad Pontificia de Comillas, 2002. 
McInerny, Ralph, Ethica Thomistica, Washington D.C., Catholic University of America Press, 1982.

McInerny, Ralph, A First Glance of St. Thomas Aquinas, Notre Dame (Indiana), University of Notre Dame Press, 1990.

McInerny, Ralph, Aquinas on Human Action: A Theory of Practice, Washington D.C., Catholic University of America Press, 1992.

Michel, Florian, La Pensée Catholique en Amérique du Nord (Réseaux Intellectuels et Échanges Culturels entre l'Europe, le Canada et les Etats-Unis), Paris, Desclée de Brouwer, 2010.

Murray, John C., We Hold These Truths (1960), Maryland, Sheed \& Ward, 2005.

NicGorski, Walter, "Leo Strauss”, Modern Age 26 (1982).

Nussbaum, Martha, Love’s Knowledge, New York, Oxford University Press, 1990.

Nussbaum, Martha, The Fragility of Goodness, Cambridge, Cambridge University Press, 1986.

Passerin D'Entreves, Alessandro, Natural Law, New York, Hutchinson University Library, 1951 (trad. it. La dottrina del diritto naturale, Torino 1954).

Petersen, Tony, "Leo Strauss, natural right and history”, en https://goo.gl/5IUOta, 2012.

Poole, Diego, "Grisez y los primeros principios de la ley natural", en Persona y Derecho 52, pp. 274-337, en http://dadun.unav.edu/handle/10171/14564.

Poole, Diego, "Lon Fuller", en Juristas Universales, vol. IV, Madrid, Marcial Pons, 2004, pp. 391 y ss.

RHonHeImer, Martin, Ley natural y razón práctica (trad. de la versión alemana de 1987), Pamplona, Eunsa, 2000 (también traducido al inglés en New York, Fordham University Press, 2000).

RHonherimer, Martin, The Perspective of Morality: Philosophical Foundations of Thomistic Virtue Ethics, Washington D.C., Catholic University of America Press, 2011.

Rommen, Heinrich A., The Natural Law: A Study in Legal and Social History and Philosophy (1936 vers. original alemana), Indianapolis, Liberty Fund, 1998.

Rommen, Heinrich A., The State in Cahtolic Thought, A Treatise in Political Philosophy, St. Louis (MI), Herder, 1945.

SHAw, Russell, "The making of the moral theologian", en The Catholic World Report, March 1996, Syracuse, NY.

Sigmund, Paul St. Thomas Aquinas on Politics and Ethics, New York, Norton \& Co Inc, 1988.

Sigmund, Paul, "Law and politics", en Kretzmann, N. y Stump, L., (eds.), The Cambridge Companion to Aquinas, New York, Cambridge University Press, 1993, p. 217.

Simon, Yves, The Tradition of Natural Law: A Philosopher's Reflections, [1965], New York, Fordham University Press, 1999. 
SToRY, Joseph, "Ley natural", en Enciclopedia Americana, ed. por Francis Lieber en 1982, en http://www.scholastic.com

Veatch, Henry, For an Ontology of Morals, Evanston (Illinois), Northwestern University Press, 1971.

VeATch, Henry, Human Rights: Fact or Fancy?, Baton Rouge (Louisiana), Louisiana State University Press, 1985.

VeATch, Henry, Rational Man (1962), Indianapolis (Indiana), Liberty Fund Inc., 2003.

Veatch, Henry, Swimming Against the Current in Contemporary Philosophy, Washington D.C., Catholic University of America Press, 1990.

Voegelin, Eric, "Nature of the law and related legal writings", en The Collected Works of Eric Voegelin, vol. 27, Columbia (MO), University of Missouri Press, 1991.

Wolf, Christopher, "Thomistic Natural Law and the american natural law tradition", en St. Thomas Aquinas and the Natural Law Tradition, Washington D.C., The Catholic University of America Press, 2004.

Wright, Benjamin, American Interpretations of Natural Law (1931), Reedit. por Routledge, London, 2016. 